\title{
Civilisations
}

Revue internationale d'anthropologie et de sciences

humaines

$53 \mid 2005$

Musiques "populaires"

\section{« Nos ancêtres les Arabes... »}

Généalogies d'Afrique musulmane

Xavier Luffin

\section{(2) OpenEdition}

1 Journals

Édition électronique

URL : http://journals.openedition.org/civilisations/613

DOI : $10.4000 /$ civilisations. 613

ISSN : 2032-0442

Éditeur

Institut de sociologie de l'Université Libre de Bruxelles

\section{Édition imprimée}

Date de publication : 1 janvier 2006

Pagination : 177-209

ISBN : 2-87263-005-8

ISSN : 0009-8140

Référence électronique

Xavier Luffin, « « Nos ancêtres les Arabes... » », Civilisations [En ligne], 53 | 2005, mis en ligne le 24 janvier 2009, consulté le 10 décembre 2020. URL : http://journals.openedition.org/civilisations/613 ; DOI : https://doi.org/10.4000/civilisations.613

(c) Tous droits réservés 


\title{
«Nos ancêtres les Arabes..." \\ Généalogies d'Afrique musulmane
}

\author{
Xavier LUFFIN
}

Résumé : De nombreuses traditions orales et écrites d'Afrique subsaharienne musulmane se rapportent à l'origine arabe de certaines populations, clans, tribus ou familles. Quel que soit le degré de véracité de ces généalogies, et malgré des contre-exemples, il est intéressant de constater que l'isläm eșt donc très souvent associé à une certaine vision de l'arabité. Plusieurs facteurs.sont à l'origine de cette interprétation : la recherche d'un certain prestige d'ordre religieux ou social, ou encore une légitimation historique et/ou politique, l'identification de l'africanité à l'esclavage. Cette quête d'arabité doit bien sûr être relativisée, d'abord parce qu'elle n'est pas systématique, ensuite parce qu'elle se retrouve aussi ailleurs dans le monde musulman. Elle tient toutefois une place relativement importante en Afrique subsaharienne.

Mots-clés : altérité, islam, généalogie, migrations, esclavage, mythes fondateurs, langue arabe, chérifisme, oralité , traditions, racisme.

Summary : Many oral and written sources in Muslim Subsaharian Africa deal with the Arab origin of various peoples, clans, tribes or families. Though this claim to an Arab origin is not systematic, and may in many cases be true, it is relevant to note that Islam in Africa is often related to Arabity. Various factors may explain this process : a claim to a religious or social prestige, a kind of political and/or social legitimacy, the identification of Africanity with slavery. Of course; this claim to an Arab genealogy has to be qualified, first because it is not systematic, then because it occurs elsewhere in the Muslim world. It has, however, a particular importance in. Subsaharian Africa.

Keywords : Alterity, Islam, Genealogies, Mịrațion, Slavery, Foundation Myths, Arabic, Sharifism, Orality, Traditions, Racism. 


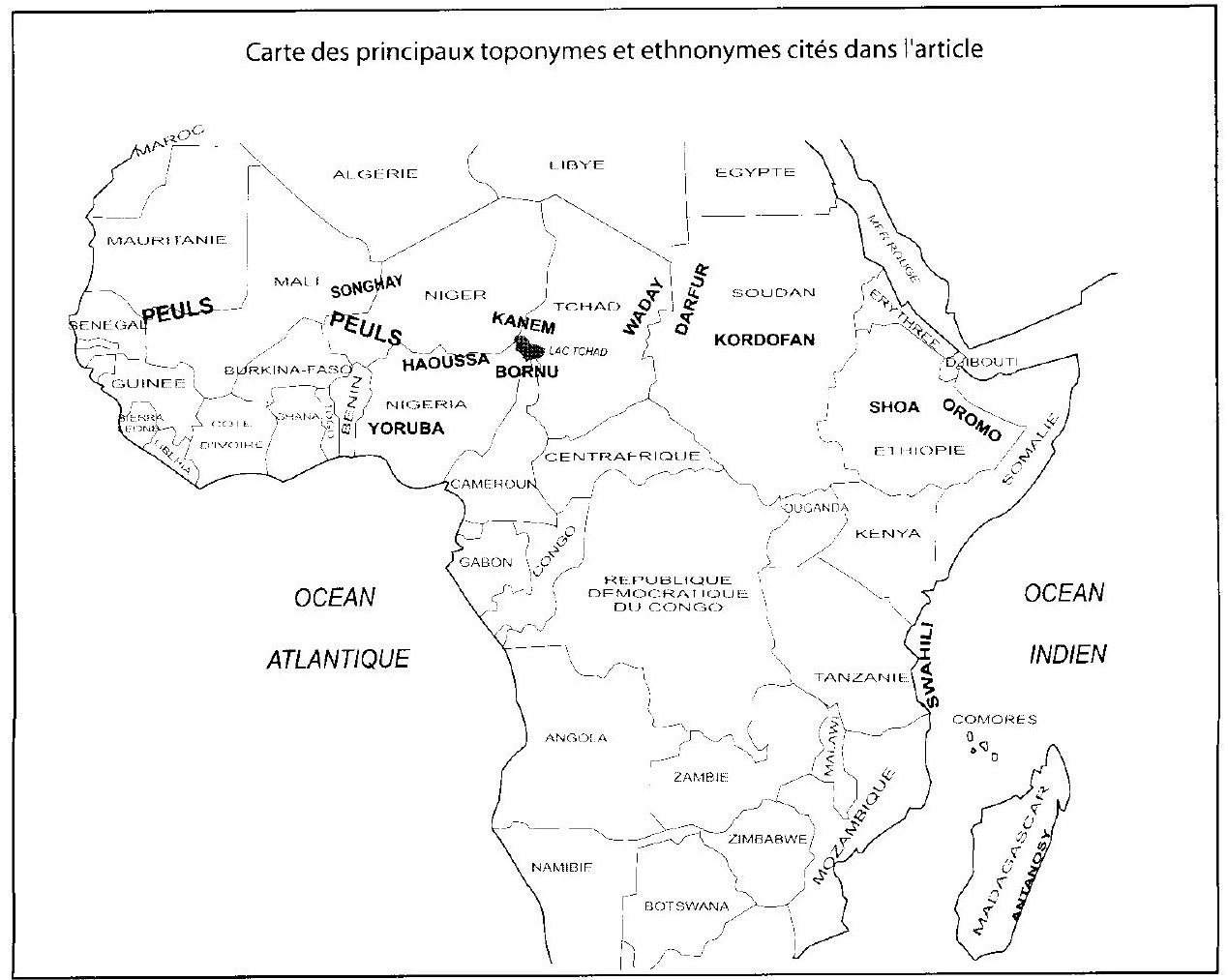

uiconque se penche sur les généalogies et les mythes fondateurs en Afrique musulmane constate que de nombreux peuples - ou quelquefois, de manière plus restrictive, certains de leurs clans ou de leurs familles - revendiquent des origines arabes. Ils fondent souvent cette assertion sur un récit plus ou moins légendaire, relatant tantôt l'arrivée d'un ancêtre arabe qui aurait épousé une princesse locale, tantôt l'installation de quelque famille prestigieuse, venue de la péninsule arabique ou du Levant. Cette tradition s'observe de l'est à l'ouest du continent. Il est vrai que les liens entre le monde arabe et l'Afrique sont très anciens et remontent dans certaines régions à la période pré-islamique. Dans des pays comme le Soudan, l'Ethiopie ou la Somalie, Arabes et Africains se sont incontestablement mêlés, et l'origine arabe de certaines grandes familles africaines ne fait pas de doute. Dans d'autres cas, leurs origines arabes sont plus obscures, mais tout autant mises en avant, avec plus ou moins d'insistance.

L'objectif de cet article n'est nullement de déterminer quel peuple ou quelle famille du continent africain est effectivement d'origine arabe et lequel ne l'est pas. Ce serait impossible dans de nombreux cas, mais surtout inutile. Nous tenterons plutôt de comprendre pourquoi certains insistent tant sur leurs origines arabes, pourquoi les uns les mêlent à leur passé africain, tandis que les autres y voient un élément qui exclut leur africanité. 
En outre, certains musulmans du continent noir assument bien sûr parfaitement leur identité africaine, sans recourir à une quelconque généalogie arabe. Nous ne prétendons donc pas, par les exemples qui suivent, résumer l'Histoire de l'Afrique musulmane à une simple quête d'arabité. Mais l'étendue des cas, dans le temps comme dans l'espace, mérite tout de même qu'on s'y attarde.

\section{Le récit de l'ancêtre arabe : quelques exemples}

En Afrique de l'Est, plusieurs traditions établissent un lien «physique » entre la présence de l'islam sur le continent et le monde arabe, situé de l'autre côté de la mer. En Somalie par exemple, de nombreuses tribus clament des origines arabes, en particulier dans le nord du pays. Ainsi, la tradition de l'ancêtre Darood' est commune à plusieurs tribus, appartenant toutes au clan à qui il laissa son nom : un jour, Darood est chassé d'Arabie et il traverse la mer pour se rendre sur la côte somalienne. Arrivé au pied d'un arbre, il creuse un puits. Doombiro, la fille de Dir, souverain local, fait connaissance avec cet étranger. Mais Dir constate au retour de sa fille que le troupeau est mieux abreuvé que d'habitude et il décide de la suivre pour en connaître la raison. Darood, voyant le père de Doombiro arriver, couvre le puits d'une grosse pierre et se cache dans l'arbre. Dir essaie sans succès d'ouvrir le puits, alors Darood lui propose un marché : il descendra de l'arbre et ouvrira le puits à condition qu'il puisse épouser sa fille. C'est ainsi que Darood épousa Doombiro et fut a l'origine de certains clans somaliens (Mansur, 1995: 118). La même histoire, qui est peut-être la déformation d'une tradition pré-islamique, se retrouve chez les Oromo d'Ethiopie, apparentés aux Somali.

Un autre grand clan somali, celui des Isaq, tient aussi pour ancêtre éponyme un

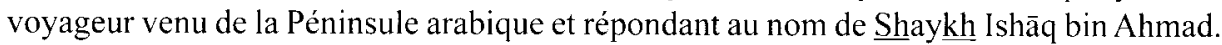
Les ancêtres d'Ishāq seraient originaires d'Irak, mais se seraient installés à Médine, puis au Yémen, dans le Hadramawt. Un jour, Ishāq vit Dieu en rêve, qui lui ordonna de répandre l'islam au-delà des mers. Il traversa alors le Golfe d'Aden en voguant sur son tapis de prière et il s'installa en Somalie (Bader, 2000 : 105; Hrbek et El Fasi, 1997 : 90 ).

Au Soudan, certains peuples musulmans tentent de se rattacher à Ja'al - ou à un Ja'alī (tribu arabe du Soudan) qui aurait épousé une princesse locale : c'est le cas de certains clans Bejja des Bānī 'Amr et d'autres clans du Dārfūr et du Wadāy (Holt et Daly, 1988 : 5). Selon des généalogies compilées à partir du siècle dernier - mais qui lui sont antérieures - les Funj - un important royaume de la région - revendiquaient une origine ummayyade? ${ }^{2}$.

En Ethiopie, les communautés musulmanes enracinèrent leurs origines dans la région de la Mecque, comme la dynastie qui régna sur le royaume de Shoa, du $9^{\mathrm{e}}$ au $13^{\mathrm{e}}$ siècle, et qui prétendait descendre des Banū Makhzūm, puissant clan qurayshite - les Quraysh étant la tribu dont était issue le Prophète. La dynastie qui lui succéda, celle des Waslama, revendiquait elle aussi une lointaine ascendance arabe (Hinds, 1991: 139a; Cerulli, $1997: 407$ sq.).

1. Nous proposons de citer les noms propres et les concepts étrangers selon l'orthographe de leur langue d'origine arabe, swahili, somali ou autre - sauf s'il s'agit d'un terme passé en français de manière bien établie (Soudan et non Sūdān par exemple). Dans la bibliographie, nous conservons l'orthographe de la langue de publication.

2. Holt, P et M.W. Daly, 1988: 26 sq. Les exemples de généalogies arabes au Soudan sont très nombreuses. Voir aussi Trimingham, J.S., 1965 et Mūsā al-Zayn, Q., $1998: 43$ sq. 
Sur la côte swahili, en Afrique orientale, plusieurs traditions orales mais aussi des chroniques locales comme celle de Lamu rapportent que des hommes envoyés par le calife ummayyade 'Abd al-Malik (685-705) s'installèrent dans la région, ou qu'au contraire deux frères de la famille arabe des Julanda, après leur défaite contre le même calife, vinrent s'y réfugier. D'autres traditions font état de familles yéménites et omanaises établies dans la région depuis des temps reculés (Allibert, 1988:112).

En poursuivant vers le sud, on constate qu'aux îles Comores - qui présentent de nombreuses affinités avec le monde swahili - plusieurs traditions orales mettent en évidence les familles arabes qui s'y seraient installées : tantôt des Ummayyades, qui auraient fondé les villes de Domoni et Ntsaweni, tantôt des Irakiens ou des Arabes de la Péninsule arabique, voire des Iraniens venus de Shiraz (Allibert, 1988: 113 sq.; Lafon, 1988-89: 99).

Encore plus bas, à Madagascar, les communautés musulmanes installées depuis de nombreux siècles sur les côtes orientale et occidentale de l'île insistent sur leur ascendance arabe : les Antanosy par exemple considèrent que leur ancêtre Raminia est arrivé de la Mecque (Esoavelomandroso, 1991 : 368). Quant aux Zafikazimambo, ils rapportent qu'à une époque reculée, le Calife de la Mecque envoya leurs ancêtres sur l'île, embarqués dans de grands canots, afin d'instruire la population locale. Le prince de Matatana accepta de donner sa fille en mariage au chef de cette délégation arabe, à la condition que leur descendance portât le nom de la fille en question, Kazimambo (Allibert, 1988 : 115).

Dans cette autre aire culturelle que constituent la région subsaharienne et l'A frique de l'Ouest, des récits similaires circulent. Ainsi, de nombreuses populations musulmanes du Tchad, arabophones ou non, revendiquent une origine yéménite : c'est le cas des Juhayna (répartis entre le Soudan et le Tchad, nous y reviendrons plus loin), des Bagirmi, des Tamagra... ${ }^{3}$.

Shaykh Jedda, un Palestinien d'origine tchadienne rencontré en 1995 dans le « Quartier Africain $»^{4}$ de Jérusalem, dont il était alors le mukhtār, insistait lui aussi sur le fait qu'il était né au Tchad d'une famille « arabe pure », arrivée il y a plusieurs générations de la Péninsule arabique et portant le même nom que la célèbre ville saoudienne.

La tradition est ancienne dans la région du Tchad, puisque chez les Zaghāwa, la dynastie des Sēfuwa, qui domina la région du Kānem (Tchad) dès le $11^{\mathrm{e}}$ siècle, prétendait avoir pour ancêtre le héros yéménite Sayf Bin Dhī Yazān. Ce cas-ci est intéressant car parallèlement à leur généalogie arabe, certains souverains Sēfuwa ne renièrent pas non plus leurs origines locales, à la fois pour enraciner la légitimité de leur présence dans le Kānem et pour récupérer le passé des Duguwa, qui avaient créé dans la région un État apparemment fortement structuré (Lange, 1991 : 167 sq.).

D'après Babou Condé, un griot du Haut-Niger qui a livré sa version de l'Histoire de l'ancien Mali à Camara Laye, il existait autrefois entre la Guinée et le Mali le royaume de Tabon. Ce royaume aurait été fondé dès le $7^{c}$ siècle par un certain Abdoul Wakass, venu d'Arabie. Après avoir traversé l'Egypte, il serait allé plus à l'Ouest jusqu'à arriver

3. Jullien de Pommerol, $1997: 14$ et surtout note 8, pour un complément bibliographique : 19.

4. Ce quartier, appelé al-jälia al-afriquyya ou encore habs ad-damm en arabe, est situé dans la vieille ville de Jérusalem-est. Il est habité par des Palestiniens musulmans d'origine africaine : Soudanais, Tchadiens, Nigériens, Sénégalais... Leurs ancêtres étaient des commerçants ou des pélerins qui, après un long périple à travers la péninsule arabique et le Proche-Orient, s'installèrent dans la ville sainte. 
chez les Tabonka. Ceux-ci en firent leur roi car il était lettré et connaissait l'arabe. Abdoul Wakass épousa alors une fille de la famille Camara et unifia le pays (Laye, 1978 : 33).

La dynastie songhay des Dia, quant à elle, prétendait venir du Yémen. Selon une légende, deux frères étrangers seraient arrivés dans la région de Kukia, ancienne capitale de l'empire songhay. L'aîné aurait affronté le Démon du fleuve qui régnait alors sur la région et l'aurait vaincu. Il serait alors devenu le roi de la région et aurait ainsi fondé la dynastie des Dia. Ce dernier terme serait une déformation du premier mot de la phrase suivante : $j \bar{a}^{\prime}$ [min al-Yaman], « il est venu du Yémen ». Une légende similaire aurait également cours dans le Kordofan, le Ghana, le Bornou et le Wadāy (Diop, 1987 : 162).

Au Nigeria, certains Yoruba convertis à l'islam prétendent avoir pour ancêtre un certain Lamurudu (probablement une déformation de Nimrūd) qui aurait régné à la Mecque. Selon d'autres, comme le Sultan Muhammad Bello (1779-1837), les ancêtres des Yoruba auraient été chassés d'Irak par un certain Ya'rub Ibn Qahtān et forcés de traverser l'Egypte, le Soudan, l'Ethiopie puis d'errer toujours plus à l'Ouest pour finalement arriver au Nigeria. Le même Ya'rub serait d'ailleurs à l'origine de l'ethnonyme Yoruba'.

Chez les Haoussa du Nigeria, certaines traditions se rapportent également à Lamurudu cité plus haut, mais une légende plus répandue soutient que leur ancêtre commun est le prince Bayajida, déformation de l'arabe Abū Yazīd. Ce dernier, originaire de Bagdad, aurait tué un serpent qui terrorisait la reine locale, Daura. Celle-ci accepta alors de l'épouser et lui donna un fils, Bawogari. Puis Bayajida eut un autre fils d'une concubine, Karbogari. Chacun des fils eurent eux-mêmes sept fils, chacun à l'origine d'un des quatorze royaumes de la région. Cette légende se retrouve dans la tradition orale, mais aussi dans la Chronique de Kano, un manuscrit arabe local remontant au $17^{\mathrm{e}}$ siècle qui relate l'histoire de cette ville en se basant sur les traditions locales ${ }^{6}$. L'origine arabe des Haoussa, justifiée par ces traditions, fut en outre relayée ultérieurement par les chercheurs occidentaux, qui considéraient que cette légende reflétait une réalité historique (Adamou, 1991 : 179).

Au Sénégal également, le lien de certains peuples - ou de certaines familles - avec les Arabes est souvent mis en évidence. Dans le royaume wolof du Walo, le roi était choisi au sein de trois lignages maternels : maure, sereer-lebu ou peul-mandingue (Diouf, $1994: 30$ ).

Lors d'un voyage en Mauritanie en 1995, une Maure nous livra l'explication suivante concernant l'origine de la tribu peule des humr al-julüd, littéralement les «PeauxRouges » : selon elle, il s'agirait des descendants de guerriers arabes. Ayant perdu le contact avec les autres Maures de la région, ils se seraient métissés avec des femmes peules et auraient adopté leur langue. C'est pourquoi ils ne seraient pas noirs mais de teint cuivré... et auraient des facilités évidentes pour apprendre l'arabe, resté présent quelque part dans leur esprit.

5. Plusieurs auteurs rapportent et discutent ces généalogies. Voir notamment dE MoreAs, P. F., Yoruba Origins revisited by Muslims, in Self-Assertion and Brokerage: Early Culural Nationalism in West Africa, Birmingham (ed. P. F. Farias et K. BARBER), $1990: 109$ sq; Davidson, B., African Civilization revisited, New Jersey, 1995 : 83; PfF.., J. D. Y., Religious Encounter and the Making of the Yoruba, Bloomington, $2000: 283$.

6. Palmer, 1908 : 58 à 98 . Pour une analyse plus récente de l'historicité de la légende de Bayajida, voir Mahamane, $1999: 49$ sq. 
La liste des exemples précités n'est pas exhaustive et l'on pourrait bien sûr continuer à énumérer les histoires et traditions locales se rattachant aux origines arabes des populations africaines musulmanes. Mais cela n'est pas l'objectif de cet article, nous n'avons voulu citer que quelques cas particulièrement représentatifs de ces traditions.

Il est intéressant de noter d'emblée que si l'ancêtre arabe revendiqué dans les cas précités peut être originaire de pays assez divers - l'Irak, l'Egypte... - la péninsule arabique est la région la plus récurrente. En fait, cette région est considérée comme le berceau de la culture arabe, on l'appelle d'ailleurs jazirat al- 'arab, la " péninsule des Arabes ». Les traditions arabes rapportent en effet que les ancêtres de tous les Arabes sont Qahtān et 'Adnān : les descendants du premier peuplaient le Yémen et ceux du second le Hijāz, ensuite il se sont dispersés dans les autres régions (A1 Hūt, 1979 (1955) : 165 sq.). En outre, c'est dans la péninsule arabique que l'islam a été révélé et que se trouvent ses principaux lieux saints. Avoir un ancêtre venu de la Péninsule arabique renforce donc doublement la qualité de cette origine arabe tant revendiquée.

\section{Variantes : origines persanes et berbères}

Si l'ascendance arabe est de loin la plus recherchée, il arrive aussi que certaines familles d'Afrique de l'Est se prêtent des origines persanes. Ainsi, selon les chroniques swahili, notamment la Chronique de Kilwa, le premier sultan de la ville était un Persan originaire de Shiraz qui avait épousé une princesse locale. Plus tard, les familles de négociants s'attribuèrent le même type de généalogie arabe ou persane, de manière à s'élever socialement (Matveiev, $1991: 293$ ).

En Somalie, plusieurs tribus se réclament aussi d'une origine persane, en particulier sur la côte, dans la région des Banādir (du persan bandar, "port »). Par exemple, la tribu des Shanshiyya tire son nom d'une région d'Iran, tandis qu'à Mogadiscio un quartier ancien habité à l'origine par des marchands iraniens portait le nom de Shangani (qu'on retrouve aussi sur la côte swahili), du nom d'un quartier de Nishapur (Mukhtar, $1995: 5)$.

Aux Comores également, on raconte qu'il y a bien longtemps un Iranien, contraint de fuir sa ville natale de Shiraz, se réfugia avec ses six fils sur l'île d'Anjouan (Allibert, 1988: 114).

En Afrique de l'Est, les références à cette ascendance persane est ancienne - on en recense dès le début du $16^{\mathrm{C}}$ siècle - et on attribue en outre à ces Shirazi toute une série d'innovations, telles que l'utilisation de la pierre comme matériau de construction, la fabrication de la chaux, le tissage du coton... (Freeman-Grenville, $1998: 499 \mathrm{ab}$.).

En Afrique de l'Ouest, il existe également une tradition, certes moins répandue, liant certains peuples aux Berbères. Makhtar Diouf voit dans les Peuls des descendants de Berbères sahariens (Diouf, $1994: 26$ ), tandis que selon certaines traditions d'Afrique occidentale, le Royaume des Songhay aurait été fondé par deux Berbères qui auraient été accueillis par la population locale, qui finit par choisir ses rois parmi leurs fils (Stamm, $1993: 40$ ). 


\section{Les raisons de la quête d'arabité}

\subsection{Islam et arabité}

Mais pourquoi revendiquer un ancêtre arabe ? Cela confère-t-il un prestige particulier, une certaine légitimité ?

De manière générale, on peut bien sûr mettre en avant le besoin d'un mythe des origines, constant dans l'ensemble des civilisations. En Europe comme ailleurs, de nombreux Etats ont exagéré ou altéré leur Histoire, voire tout bonnement créé des mythes afin de prouver l'ancienneté de leur culture et son rayonnement. Cela leur a permis de mieux asseoir leur légitimité, souvent même leur supériorité culturelle et politique : exaltation des origines franques par la noblesse française, réappropriation de son passé païen par la Grèce moderne...

En Afrique, on retrouve le même processus. En dehors du monde musulman, les Amharas chrétiens d'Ethiopie par exemple ont eux aussi insisté sur leurs origines solomonides - la dynastie royale serait issue de l'union entre le Roi Salomon et la Reine de Saba - dans le même but d'acquérir un certain prestige grâce à des ancêtres illustres, cités dans les Ecritures. Mais la quête d'arabité prend toutefois des formes particulières, pour des raisons propres à l'islam d'une part, à l'Histoire de l'Afrique d'autre part.

L'islam en tant que religion ne fait pas de différence entre les Arabes et les autres musulmans, ni même entre les peuples de manière générale. Le Qur'ān insiste à maintes reprises sur l'universalité de son message, et certains hadīth ${ }^{7}$ mettent même l'accent sur l'égalité entre les races par rapport à la religion. A titre d'exemple, citons un hadīth célèbre : bu 'ithtu ilā al-ahmar wa-l-aswad, soit «J'ai été envoyé auprès des Blancs comme auprès des Noirs $»^{8}$.

Pourtant, un élément de taille confère aux Arabes un rôle particulier dans l'Histoire de l'islam : même si son message se veut universel, le Qur'ān a été révélé en arabe à un prophète arabe. La langue coranique est d'ailleurs considérée comme le seul miracle dans la religion musulmane. On parle de l'i jāaz, l'inimitabilité du Qur'ān'. Par la force des choses, les Arabes furent les premiers à propager l'islam et à gouverner l'umma, la communauté des croyants, même si cette situation changea par la suite. Les Arabes ont donc une place particulière non pas dans l'islam - qui est clair sur ce point - mais dans sa diffusion. Dans le cas d'individus ou de familles - car les traditions précitées s'appliquent parfois à un peuple, parfois à une famille ou à un clan - une généalogie garantissant une origine arabe offre donc des avantages à la fois politiques et religieux.

Les origines arabes d'un clan lui donnent une assise politique plus importante dans l'imaginaire populaire. On a vu aussi que dans certains cas - le Sénégal par exemple avoir une origine déterminée est même un pré-requis pour prétendre au pouvoir. Le pouvoir politique est donc lié à une certaine noblesse des origines, liée ici au prestige de l'arabité, que démontrent bien les « mythes royaux » haoussa ou yoruba.

7. Propos prêtés au Prophète et recueillis dans les ouvrages qui constituent la Sunna. Ils constituent pour les Sunnites la référence principale après le Coran.

8. Nous reviendrons plus loin sur l'interprétation de ce hadīth.

9. Voir par exemple Anghelescu, 1995: 13 sq et 27 sq. 


\subsection{Le nasab}

Un autre élément à ne pas sous-estimer pour tenter de comprendre ce phénomène est l'importance du nasab, c'est-à-dire la filiation, la généalogie, chez les Arabes eux-mêmes. Le nasab constitue effectivement le principe fondamental de l'organisation sociale chez les Arabes et il a donné lieu, dès l'avènement de l'islam, à une importante littérature. Parmi les nombreux ouvrages de généalogie, le plus important fut rédigé par Hishām Al-Kalbī, au $8^{c}$ siècle : le Jamharat al-nasab. Avec l'arrivée de nombreuses populations non-arabes au sein de l'umma musulmane, l'intérêt pour le nasab se verra consolidé et permettra notamment de déterminer le degré de « noblesse » d'une famille (Rosenthal, $1993: 967$ b à $969 a)$.

Mais ces généalogies sont souvent falsifiées. L'Historien Yāqūt (13e siècle) rapporte qu'al-Jāhiz, célèbre écrivain du $9^{e}$ siècle sur lequel nous reviendrons plus loin, aurait proposé à un linguiste d'origine persane de lui forger une généalogie le rattachant à une tribu bédouine, afin d'encore renforcer sa notoriété en tant que connaisseur de la langue arabe (Touati, $2000: 77$ ).

Au siècle suivant, le célèbre Ibn Khaldūn consacra quelques pages de son fameux ouvrage, al-Muqaddima («l'Introduction ») à critiquer le comportement de nombreux clans ou chefs de clans arabes qui « prétendent à des généalogies éclatantes. Ils voudraient descendre de familles célèbres pour leur bravoure, leur noblesse ou leur renom ${ }^{10}$. Et de citer ensuite de nombreux exemples de généalogies arabes douteuses, en particulier auprès des Zanāta, une tribu berbère importante à l'époque, en insistant sur le fait que ces chefs de tribus berbères cherchent par ces généalogies une légitimité politique. Ailleurs, il défend l'origine shérifienne (voir plus loin) - contestée par certains de ses contemporains - de l'imām al-Mahdī, fondateur de la dynastie des Almohades (Ibn Khaldũn, éd. non datée : 39 sq.).

D'autre part, dans son étude sur la poésie anté-islamique, l'auteur égyptien Taha Hussein (1889-1973) considère que plusieurs poèmes prestigieux considérés généralement comme remontant à cette époque reculée auraient en réalité été composés à l'époque islamique. L'une des raisons de cette imposture aurait été de prêter à certains clans et tribus arabes un prestige particulier, notamment au niveau de leur ascendance (Hussein, 1996).

Le recours à des généalogies ou a des récits permettant de prouver la qualité de son arabité s'observe donc d'emblée au sein du monde arabe lui-même.

Le phénomène se retrouve d'ailleurs dans le monde arabe à l'époque contemporaine. Un exemple récent est celui des Bahãrna, à Bahrein. La population de ce pays est composée principalement de trois groupes « socio-ethniques", les deux concepts étant liés dans la vision des Bahrayni de leur propre identité : les 'Arab, c'est-à-dire les Arabes, qui sont Sunnites, les 'Ajam, Shī'ites d'origine iranienne relativement récente, et les Bahārna. Ces derniers, également Shī'ites, se considèrent comme les premiers occupants du pays, tandis que les Sunnites leur prêtent - péjorativement - une origine iranienne. Par réaction, certains Bahārna insistent sur une tradition qui rappelle que les Bahārna sont venus il y a très longtemps du Yémen, pays si souvent invoqué pour marquer la pureté de son arabité (Holes, 1980:73).

10. Ibn Khaldūn, (éd. non datée); pour la traduction française, voir celle de Monteil, 1997 (Beyrouth, $1967)$ : 204. Dorénavant, les notes portant sur Ibn Khaldūn se référeront à ladite traduction. 
En outre, l'importante production scientifique de certaines civilisations leur conféra manifestement un aura particulier: elles sont vues comme des sociétés raffinées, bien organisées, produisant des philosophes, des historiens, des scientifiques. A titre d'exemple, l'historien du $11^{\mathrm{e}}$ siècle Abū al-Qāsim Al-Andalusī, dans son ouvrage Kitāb tabaqāt al-umam - "Le Livre de la classification des nations » - range les divers peuples de la terre parmi ceux qui ont apporté quelque chose aux sciences et ceux qui n'y ont rien apporté. Les premiers sont les Indiens, les Iraniens, les Chaldéens, les Grecs, les Byzantins, les Egyptiens, les Arabes et les Juifs. Les seconds comprennent les Chinois,les Turcs, les peuples de l'extrême Nord comme les Slaves et les Bulgares et de l'extrême Sud, en l'occurrence les Africains, mais aussi les Berbères (Abū Qāsim alAndalusī, $1912: 8$ sq.).

Plus tard, au $14^{\mathrm{e}}$ siècle, Ibn Khaldūn insistera dans sa Muqaddima sur le fait que la plupart des savants musulmans ne sont pas des Arabes mais des étrangers - en particulier des Iraniens - ce qu'il attribuera à l'oralité et au caractère nomade de la culture arabe avant et aux premiers temps de l'islam (Ibn Khaldūn : 950 sq.). Avant lui, al-Jāhiz avait déjà soulevé l'importance de l'écriture et les avantages qu'elle offre en ce qui concerne la conservation du savoir (Anghelescu, $1995: 57$ sq.).

Ici intervient donc un nouvel élément : la force de l'écrit sur l'oralité. Les Persans et les Indiens comme les Grecs ont laissé une importante littérature composée avant l'avènement de l'islam, dont une grande partie sera d'ailleurs traduite en arabe. L'écrit permet à une culture de continuer à exister, de laisser un témoin, d'autant plus fort qu'il provient de la culture en question et pas d'un œil extérieur. Or, certains royaumes africains antérieurs à la pénétration de l'islam dans le continent étaient très étendus et bien organisés, mais ils ne laissèrent pas ou peu de traces écrites, qui auraient permis d'en témoigner et d'être reprises auprès des observateurs arabes.

Dansle mêmeordre d'idée, ladifférencesur le plan de laculture matérielle - architecture, beaux-arts... - entre la culture arabe et ses prédécesseurs iraniens, grecs ou autres d'une part, et les cultures africaines a également joué un rôle dans la dépréciation par certains Africains de leur propre culture. En effet, cette différence sur le plan matériel fut perçue quelquefois comme un élément d'infériorité. Ainsi, il est révélateur qu'en kiswahili le terme $k u$-staarabu ou son synonyme ku-staarabika, dérivé de l'arabe ista'raba ( « s'arabiser», en arabe), signifie " être ou devenir intelligent, sage, instruit, civilisé » Quant au sens originel du terme, «s'arabiser», il est passé au second plan. D'autres termes, dérivés de ce verbe, font partie du même champ sémantique : ustaarabu: civilisation ", mstaarabu : " homme civilisé, bien éduqué, au comportement correct " (Heylen, 1977 : 153; Lenselaer, 1983 : 498). Les Swahili, Africains islamisés vivant sur la côte orientale de Tanzanie et du Kenya, ont tôt fait de se distinguer des Africains de l'intérieur des terres. Par la religion qu'ils ont adoptée, mais aussi par le nouveau mode de vie qu'ils ont en même temps acquis : vie citadine, occupation commerciale, supériorité matérielle, différence d'habillement, nouveau style d'habitat... Dès lors, de nombreux Swahili ont eux aussi recours à des généalogies leur permettant de se désigner comme Warabu - «Arabes » en kiswahili - ou Shirazi, c'est-à-dire Persans, des commerçants venus d'Iran et notamment de la ville de Shiraz s'étant installés il y a plusieurs siècles sur la côte orientale de l'A frique (Khalid, $1977: 52,73$ ).

Tenter de mesurer le degré de civilisation d'un peuple par ses seules réalisations matérielles ou littéraires - faisant fi de la richesse de ses traditions orales par exemple - ne 
peut assurément conduire qu'à un jugement tronqué. Mais le fait est que de tels jugements étaient bien ancrés dans l'imaginaire des Arabes qui étaient en contact avec les Africains. En tout cas, la maigre place qu'ils accordaient à ces derniers dans l'Histoire participe certainement à l'explication de cette mise en évidence de leurs origines arabes, alors que ce phénomène est très peu observable chez d'autres peuples musulmans non-arabes, comme les Persans ou les Turcs, qui insistent au contraire sur leur spécificité.

\section{Le rejet de la culture africaine}

Jusqu'ici, nous avons passé en revue des exemples d'arabisation dont l'objectif était la mise en valeur d'un ancêtre glorieux, la recherche d'une légitimité politique ou d'un pouvoir spirituel ou encore le rattachement à une sphère culturelle jugée plus valorisante. Mais ces généalogies ne remettent guère en cause le passé non-arabe des peuples concernés : de nombreux Somali se disent d'origine arabe, cela ne les empêche pas de conserver leur langue et leurs propres traditions, tout comme les Tigréens ou les Haoussa. La recherche d'origines arabes par un clan voire par un peuple entier peut revêtir une forme beaucoup plus complexe : le rejet de l'africanité.

Le cas du Soudan est particulièrement révélateur : il s'agit d'un pays où se côtoient de nombreux peuples, de confessions diverses, où se parle un important nombre de langues. Cette variété est toutefois beaucoup plus forte dans le sud du pays, le nord présentant à première vue une dimension plus uniforme. En effet, même s'il y a des régions où on parle le nubien, le tigréen, le bedawi ou d'autres langues encore, l'arabe y est de loin la langue dominante, tout comme l'islam y est largement majoritaire. La plupart des tribus arabophones installées dans le Nord du pays offrent une grande variété de types physiques, où les traits africains sont souvent très présents, mais elles se considèrent toutes comme arabes. Jacques Berque a résumé en une phrase brillante la situation culturelle dans le Nord du pays : " les Soudanais du Nord vivent une africanité sans négritude. Ils se voient arabes et nullement noirs, mais "rouges »; les Nègres, selon eux, tendent au « jaune » (Berque, $1999: 210$ ).

Encore une fois, la généalogie joue un grand rôle pour justifier, « légitimer »l'arabité des gens du Nord : Barābra, Ja'aliyyīn (sing. : Ja'alī), Juhayna, tous disent avoir un ancêtre arabe notoire. L'ancêtre le plus sollicité est manifestement Ibrāhīm Ja'al - éponyme des Ja'aliyyīn - lui-même un descendant d'al-'Abbās, oncle du Prophète Muhammad. En réalité, il semble que de nombreuses tribus du Nord sont en fait constituées de Nubiens, arabisés au fil du temps par les mariages avec des Arabes. Le système matriarcal qui avait cours dans les royaumes nubiens facilita grandement leur arabisation: en effet, les descendants des Arabes qui se mariaient avec des femmes locales obtenaient petit à petit le pouvoir, puisqu'il passait aux fils par l'intermédiaire de leurs mères (Abd AlRahim, 1973:31).

Certaines tribus des Barābra, comme les Sukkut et les Mahas, ont pourtant conservé leur propre langue, un des nombreux dialectes du nubien, vestige de leurs origines réelles. Les Juhayna eux disent descendre d'une tribu d'Arabie, qui émigra d'abord en Egypte puis au Soudan, tout comme les Rufā'a (Holt et Daly, $1988: 3$ sq.).

Ce processus continua encore pendant la période coloniale : de nombreuses sources britanniques des $19^{\mathrm{e}}$ et $20^{\mathrm{c}}$ siècles parlent de detribalized Africans à propos des Africains 
qui s'étaient convertis à l'islam et qui, par la même occasion, abandonnaient l'ensemble de leur culturer ancestrale : langue, coutumes, village d'origine et même liens familiaux ${ }^{12}$.

Au Kenya et en Tanzanie, certains Swahili se qualifient eux-mêmes de Warabu, «Arabes », selon que leur père, leur grand-père, leur arrière-grand-pẹre ou un ancêtre plus lointain est originaire de la Péninsule arabique (Khalid, 1977 : 53). Dans ce cas, il ne s'agit donc plus seulement de revendiquer un lointain ancêtre arabe, mais bien de se considérer comme Arabes à part entière, en reniant totalement ou largement ses origines africaines. Pourquoi la recherche de l'arabité s'accompagne-t-elle ici d'un rejet de la culture africaine? Plusieurs pistes peuvent être dégagées.

\subsection{L'arabisation comme phénomène général}

Tout d'abord, un élément d'ordre général, justement souligné par Mazrui (1973 : 31), doit être considéré ici. L'arabisation n'a pas accompagné l'islamisation uniquement au Soudan ou en Mauritanie. Le cas du Proche-Orient et de l'Egypte est particulièrement parlant : lors de la conquête de cette région - à l'exception de la Syrie - les Arabes venus de la péninsule étaient bien sûr inférieurs en nombre aux autochtones, et ceux-ci avaient derrière eux un passé culturel aussi ancien que riche et varié. Pourtant, après quelques siècles, parfois après quelques générations, la grande majorité des musulmans du ProcheOrient se considéraient comme Arabes, et non comme «Byzantins musulmans », par exemple, pour oser un terme irréaliste. Parallèlement, les autochtones qui conservèrent leur foi chrétienne gardaient aussi souvent - pas toujours - leur identité culturelle et linguistique non-arabe ou «pré-arabe». C'est le cas des Assyro-Chaldéens et des Coptes.

Le lien entre islam et arabité est donc particulièrement fort et l'arabisation du Nord du Soudan participe - en partie - d'un phénomène général d'acculturation observé ailleurs depuis les premiers temps de l'islam. Notons que plus tard, un phénomène similaire sera observable dans l'Empire ottoman : un chrétien se convertissant à l'islam - qu'il soit Grec, Slave ou Albanais - devient musulman, mais aussi Turc, la religion musulmane dans les Balkans étant alors intimement liée à la population qui l'apportait.

\subsection{Le concept de Jähiliyya}

L'avènement de l'islam constitue pour les Musulmans leur nouvelle référence chronologique. Il y a désormais ce qui était avant l'islam - période nommée Jāhiliy̧va, qui signifie «l'époque de l'ignorance »- et le monde après la révélation divine.

Les Arabes musulmans se sont largement désintéressés de ce passé non-islamique, même s'ils y font encore référence dans le domaine de la poésie par exemple: les Mu allaqät, poèmes rédigés durant la Jähiliyya restent en effet la référence incontournable en la matière. Ceci n'est pas sans rappeler le dilemme de Dante qui doit placer Homère parmi les hôtes des Enfers, en sa qualité de païen. Il semble toutefois qu'ils aient gommé toute référence à la religion pré-islamique dans l'oeuvre de ces poètes - à moins qu'il s'agisse là d'une preuve de leur rédaction relativement tardive (Anghelescu, 1995 : 33 sq.). 
Le passé anté-islamique des Arabes est donc largement proscrit et on y fait rarement référence, sauf s'il est lié à un passage du Qur'ān : l'expédition du roi éthiopien Abrāhā au Yémen, quelques traditions judéo-chrétiennes... Il ne refera surface qu'avec l'avènement du nationalisme arabe. C'est alors que les Irakiens et les Egyptiens par exemple récupéreront respectivement leur passé akkadien et pharaonique, auquel jusque là seuls les Européens s'intéressaient ${ }^{13}$.

Par ailleurs, l'islam tolère les ahl al-kitāb, les « Gens du Livre »-juifs et chrétiens (et dans une certaine mesure zoroastriens) - et leur conversion à l'islam n'est pas obligatoire, en théorie du moins. Par contre, les tenants des autres religions qui n'ont pas de Livre révélé et qui ne croient pas en l'Unicité de Dieu sont méprisés. Or, si le christianisme - et le judaïsme - étaient certes présents en Ethiopie et au Soudan, les religions traditionnelles y étaient généralement plus répandues. Pour un Soudanais musulman, substituer à ses racines dinka ou nuer une origine arabe permet donc d'effacer un passé honteux sur le plan spirituel.

\subsection{Lesclavage}

Nous avons déjà insisté sur le fait que la religion musulmane ne différencie pas les peuples selon une échelle de valeur. Pourtant, l'image des Africains dans le monde musulman est souvent associée à l'esclavage, quoi qu'en disent certains. En effet, quelques auteurs considèrent que si l'esclavage a été pratiqué par les musulmans, il n'aurait en tout cas pas visé spécifiquement les Africains. Par ailleurs, selon eux la notion d'esclavage ne serait pas la même qu'en Occident, se rapprochant même dans certains cas de liens quasi familiaux : Khalid par exemple va jusqu'à définir la 'ubüdiyya-qu'il se refuse à traduire par « esclavage» - comme une institution où le 'abd («l'esclave») est adopté par un maître et soumis à un contrat de travail et où les restrictions de sa liberté sont atténuées par la sécurité sociale dont il bénéficie... ${ }^{14}$ Cette théorie, mélange de romantisme, de paternalisme, de « relativisme culturel » et de récupération politique, arrange à la fois certains intellectuels arabes, africains et européens. Elle est pourtant assez éloignée de la vérité.

Sans entrer dans les détails, il est vrai que l'islam a amélioré le statut des esclaves, notamment en favorisant leur affranchissement et en interdisant l'asservissement de musulmans - en théorie du moins, car cette règle ne fut pas toujours respectée ${ }^{15}$. Il est vrai aussi que le cas des Mamlūk, ces dynasties d'esclaves d'origine turque ou caucasienne qui dirigèrent $l^{\prime}$ Egypte du $13^{\mathrm{C}}$ au $16^{\mathrm{e}}$ siècle, constituent un phénomène propre à l'islam. Mais cela ne fait pas de l'esclave un homme comme les autres : un esclave, pour les musulmans comme pour les autres cultures qui eurent recours cette pratique, appartient à

13. Sur la récupération du passé pré-islamique par l'Egypte, voir par exemple Coudougnan, G., Nos ancètres les pharaons, Dossiers du CEDEJ, Le Caire, CEDEJ, 1988

14. Par exemple Khalid, $1977: 94$ sq. Même dans la littérature occidentale, on retrouve des positions similaires. Citons par exemple Naipaul, 1979, qui dans le second chapitre de son roman donne une version presque idyllique de l'esclavage sur la côte orientale de l'A frique : « Un Africain, un cnfant de la forêt, (...) préférait ètre protégé par une famille étrangère que de se trouver scul au milieu d'Africains inconnus et hostiles (...). Les esclaves, ou les gens qui pouvaient être considérés comme esclaves, voulaient le rester ". (traduction française de Clarence, $1982: 23$ ).

15. dans le cas de l'A frique, voir par exemple, Mbow , 1999: 93. 
son maître. Par ailleurs, l'esclavage était une pratique largement répandue dans le monde musulman, quels que soient les préceptes de la religion à son égard. Dans son analyse de la fameuse révolte des esclaves africains dans le sud de l'Irak ( $9^{\circledR}$ siècle), l'historien arabe contemporain Faysal al-Sāmir fait clairement la différence entre les préceptes de l'islam par rapport au statut légal de l'esclave et la réalité sociale que celui-ci vivait au quotidien (al-Sāmir, $2000: 19$ sq.).

Bien sûr, le monde musulman n'a pas «inventé » l'esclavage : il existait dans le Monde antique et à Byzance, puis aux Amériques à partir du $16^{\mathrm{C}}$ siècle. De nombreuses sources médiévales arabes évoquent la pratique de l'esclavage chez les Africains avant l'arrivée des musulmans. Al-Maqdisī par exemple, au $10^{\circledR}$ siècle, rapporte que ce sont les Zunūj - les Africains - qui vendent leur semblables aux marchands d'esclaves, tandis qu'Ibn Battūta, au 14' siècle, décrit la présence d'esclaves auprès des dignitaires qu'il rencontra au Bilād as-Sūdān (Al-Maqdisi, 1903 : 69; Ibn Battūta, 1990 : 393 sq.). Mais le fait est que si les Africains n'étaient pas les seuls à être asservis - contrairement à ce qui se passait en Amérique du Nord avant l'abolition de l'esclavage - ils ont malgré tout fini par constituer la principale source d'esclaves dans le monde musulman, à tel point que la langue arabe a souvent associé la peau noire et la condition d'esclave : le terme 'abd - " esclave, serviteur » a en effet très tôt servi à désigner les Africains de manière générale. 'Antara ibn Shaddād, par exemple, l'un des auteurs des Mu'allaqāt, célèbres poèmes de l'époque pré-islamique, comparait la robe d'un chameau à la peau d'un esclave, sans préciser l'origine de ce dernier (al-Zawzānī,1985). L'auteur - lui-même de mère africaine - voulant mettre en évidence la couleur noire de ce chameau, il va de soi pour lui qu'un 'abd est noir de peau. On peut relever d'autres exemples au cours des siècles. Jusqu'à présent, le terme 'abd et son pluriel 'abid sont couramment employés au Proche-Orient, dans la langue quotidienne, pour signifier «Africain». Au Yémen, on désigne par le terme akhdām - serviteurs - une population arabophone, d'origine africaine, qui vit en paria dans de nombreuses villes du pays. Certains voient en eux des descendants d'esclaves, selon d'autres il s'agit d'Africains installés au fil du temps dans le pays. Une tradition locale prétend qu'ils sont les descendants de l'armée d'Abrāhā, ce roi éthiopien qui avait envahi le Yémen au $7^{\circ}$ siècle. Quelle que soit leur origine, le terme qui les désigne est en tous les cas manifestement péjoratif - et leur condition sociale pour le moins marginale.

En Mauritanie, le terme " harrātīn », associé aux esclaves et aux affranchis d'origine africaine joue également sur l'association entre couleur de peau et condition servile : à l'origine, ce mot d'origine arabe s'appliquait à un type de métier - le laboureur - qui en est finalement venu à signifier esclave et mulâtre. La couleur de peau foncée serait dès lors associée aux travaux des champs (et à la servilité). En berbère du Moyen-Atlas, ce terme aurait dépassé le champ sémantique de la complexion humaine, puisqu'il désignerait également une variété de datte brune, entérinant son sens plus large (Monteil, $1989: 44)$.

Il est intéressant de noter que la métonymie existe aussi dans l'autre sens. C'est-àdire que mentionner uniquement l'adjectif « noir » peut suffire pour signifier " esclave». A titre d'exemple, Ibn Rushd (12 $12^{\mathrm{e}}$ siècle) dans son Fasl al-maqāl se réfère à un hadīth rapporté par Muslim, relatant une discussion entre le Prophète et une esclave. Or Ibn Rushd mentionne uniquement la couleur de cette femme : "wa li-dhalika qãla, alayhi as-salāmu, fi's-sawdā'», soit "et c'est pourquoi (le Prophète) dit, que la Paix soit sur lui, à la Noire (...) ». La suite de la phrase indique qu'on parle bien d'une esclave, 
puisque le Prophète propose de l'affranchir en raison de sa foi « a'tiq-ha! fa inna-hā mu'minatun », soit "Affranchis-la, car c'est une croyante »(Averroès, 1996 : 143 qui cite un hadīth rapporté par Muslim). L'auteur ne ressent donc pas ici l'utilité de préciser la qualité d'esclave de cette femme, mentionner la couleur de sa peau semble suffire pour comprendre sa condition.

Certains auteurs vont plus loin en considérant que les Africains sont prédestinés à l'esclavage. Ibn Khaldūn lui-même considère que « les Africains sont en général soumis à l'esclavage, du fait de leur faible degré d'humanité et de leur proximité de l'état animal ${ }^{16}$. Plus tard, le souverain marocain Mūlāy Ismā‘īl ( 1668-1727) considérait que l'ensemble des Noirs établis dans son territoire devaient être considérés comme des esclaves. Encore au $19^{c}$ siècle, voire même au début du siècle suivant, de nombreux Arabes du Maghreb considéraient que le simple fait d'être noir de peau suffisait à justifier la mise en servitude d'un individu - ce qui donna d'ailleurs lieu à des discussions juridiques, notamment au Maroc (Hunwick et Troutt Powell, 2002 : 42).

Ainsi, si les Africains ne furent pas les seuls à subir l'esclavage dans le monde musulman, ils sont en tout cas les seuls à y être associés de manière «naturelle ». Or, le rejet le plus total de l'africanité se retrouve généralement dans les zones où l'esclavage a connu un développement important et où son abolition est récente, voire pas encore totalement effective. On a évoqué plus haut le cas des tribus arabes du Nord du Soudan, qui mettent en évidence leurs origines arabes au détriment de leurs origines nubiennes. Mais il s'agit de tribus d'hommes libres. Ailleurs, revendiquer des origines arabes efface tout doute sur les origines serviles - forcément honteuses - de la personne concernée. C'est le cas de certains Harratīn de Mauritanie, arabophones, coupés culturellement de leurs racines africaines et marqués par la honte de la servilité. C'est aussi le cas chez certains peuples du centre et du sud du Soudan, où le clivage Africain/Arabe et esclave/ homme libre est particulièrement marqué, certains associant même la résistance du Sud du pays avant le condominium anglo-égyptien à une lutte contre l'esclavage (Deng, $1995: 74$ sq.).

En Somalie également, l'esclavage a joué un rôle dans le façonnement de l'identité, mis en évidence par plusieurs chercheurs. Ainsi les Gosha de la vallée de Jubba, bien que musulmans et somalophones, sont considérés par les nomades comme un groupe ethnicosocial différent, parce qu'ils sont cultivateurs, mais surtout descendants d'esclaves, souvent d'origine oromo. Les Somaliens les appellent jareer, terme péjoratif lié à leurs traits africains, et font donc la triple équation entre esclave, infidèle et noir ${ }^{17}$.

\subsection{La différence physique}

Notons aussi que le racisme par rapport à la couleur de la peau, d'ailleurs souvent difficile à dissocier de l'esclavage, a certainement joué un rôle dans le rejet de l'africanité. Certains historiens, comme A. Mazrui, A. M. Mazrui et I. N. Shariff, prétendent que cette forme de racisme est inexistante dans la mentalité arabo-islamique. Selon eux, la

16. Ibn Khaldūn : 229. Lire également à la p. 92. Précisons tout de même que quelques lignes plus loin, l'auteur n'cst pas plus tendre avec les Arabes eux-mêmes, considérés comme « des pillards et des destructeurs en raison de leur nature sauvage $"$.

17. Par exemple Besteman, $1995: 43$ sq et Declich, 1995: 192sq. 
différenciation des hommes selon leur couleur de peau ou même le concept de " métis " (half-caste) seraient étrangers à cette mentalité (Mazrui, 1964 : 22; Mazrui, 1973 : 47 sq,; Mazrui et Shariff, 1993 : 10-11). Ils semblent négliger de nombreuses sources que nous allons aborder maintenant. En effet, si ce racisme n'est bien sûr pas exclusif, il n'empêche qu'il est présent, dans le monde arabe comme en Occident. On en arrive à la complexité du concept même de racisme : la peur ou le simple étonnement par rapport à la différence, notamment physique. La peau noire étonne, fascine, rebute. En tout cas son degré de différence, associé à d'autres caractères physiques (cheveux crépus...) ne laisse pas indifférent. Le poète du $10^{\mathrm{e}}$ siècle al-Mutanabbī, par exemple, dans un poème satirique visant $\mathrm{Abu}$ al-Misk, souverain égyptien d'origine nubienne, utilise les caractères physiques du personnage - couleur de la peau, grosses lèvres...- pour se moquer de lui, tout en rappelant ses origines serviles ${ }^{18}$.

Bernard Lewis, qui s'est penché sur la notion de racisme dans le monde arabomusulman, a rassemblé de nombreux exemples des préjugés raciaux dont étaient victimes les Africains et les Arabes d'origine africaine dans la littérature, depuis les poèmes des Aghribat al-'Arab - « les Corbeaux des Arabes », poètes arabes d'origine africaine de la Jāhiliyya et des premiers temps de l'islam, comme 'Antara, Suhaym, Nusayb ibn Rabah ou Abū Dulāma - aux « Mille et une nuits », en passant par la poésie d'al-Mutanabbī. Il reprend également de nombreuses sources historiques arabes considérant les Africains de manière peu élogieuse : faible intelligence, odeur désagréable, cannibalisme, mœurs sexuelles débridées, nudité... Certains comme Sa î̉ Al-Andalusī, considèrent même que les Noirs sont plus proches des bêtes que des humains (Lewis, 1982:17 sq.).

Plus récemment, Brahim Diop a également réuni de manière convaincante plusieurs sources arabes où les préjugés liés à la couleur de la peau donnent des Africains une image extrêmement négative : al-Hamdānī ( $10^{\complement}$ siècle) compare leur comportement à celui des bêtes sauvages, tandis qu'Ibn Butlān ( $11^{\mathrm{e}}$ siècle) considère que " plus leur peau est basanée, plus ils sont laids et incapables (...), leurs lèvres épaisses sont signe de stupidité et leurs yeux noirs indiquent la lâcheté ». Bien d'autres auteurs soulignent la laideur physique et l'absence de moralité des Africains (Diop, 1999:61 et 69 sq.; Lewis, 1983).

Sans pouvoir en quantifier l'importance, cette notion de différence par rapport à soi a certainement joué un rôle dans la mise en esclavage des Africains, par les Arabes comme par les Européens: il s'agit pour eux de gens physiquement «très » différents - de manière subjective bien sûr - à qui l'on prête des mœurs et un mode de vie tout aussi différents.

Un passage de la Muqaddima d'Ibn Khaldūn est révélateur à ce sujet : il traite de l'influence du climat sur la mentalité de l'homme, théorie inspirée de certains philosophes grecs, et explique que l'iqlimm (les géographes arabes, s'inspirant de leurs prédécesseurs grecs, divisaient le monde en sept parties, désignées par ce nom) idéal est celui où vivent les Arabes. Au plus on s'en éloigne, au plus on constate que les hommes qui y vivent sont «plus proches des animaux, vivent dans des cavernes, ignorent la religion, s'habillant de peaux d'animaux ou même restent nus... ». La couleur de la peau est directement associée à cette répartition climatique. Cela dit, les Africains et leur peau noire ne sont

18. Al-Mutanabbī, $1994: 81 \mathrm{sq}$. Rappelons également que le surnom d'Abū'l-Misk était Käfïr, ce qui signifie " camphre ", matière végétale blanche, allusion antinomique à sa couleur de peau... 
pas les seuls concernés par cet état de barbarie, puisqu'en s'éloignant du climat idéal par le Nord, on rencontre d'autres sauvages que sont les Slaves et autres Européens (Ibn Khaldūn : 58 à 62).

La diffusion de certaines traditions populaires racistes, étrangères à l'Islam, renforceront encore cette honte liée à la couleur de la peau. C'est le cas de la « Malédiction de Hām », qu'on retrouve chez les chrétiens comme chez les musulmans. Dans la tradition judéochrétienne (Genèse, IX, 25) comme en islam, on raconte que Noé (Nūh chez les Arabes) avait lancé une malédiction sur son fils Cham (Hām chez les Arabes), qui retomba sur toute sa descendance. Bien que les sources religieuses, qu'elles soient judéo-chrétiennes ou musulmanes, ne mentionnent aucunement la couleur de peau de Hām, des traditions historiques postérieures ajoutèrent qu'il était Noir et que cela faisait partie de la malédiction (Cohen, 1971 : $107 \mathrm{a}-\mathrm{b}$ ). Désormais, Hām et sa descendance seraient les esclaves de leurs frères. Cette exégèse cautionnait l'esclavage des Africains en lui donnant une origine divine, ce que s'empressèrent d'utiliser les marchands d'esclaves arabes et européens. Encore une fois, si cette théorie n'est nullement avalisée par la religion musulmane, elle est en tout cas largement relayée par de nombreux auteurs arabes. Ibn Khaldūn, par contre, critique cette légende avec véhémence, expliquant ensuite que la noirceur de la peau des Africains est due à l'influence du climat sur la physionomie. Ahmad Bābā, juriste de Tombouctou du $17^{\circ}$ siècle et lui-même africain, reprendra les mêmes arguments pour critiquer cette légende justifiant la mise en esclavage des Africains (Ibn Khaldūn : 130sq, Mbow, 1999 : 99 sq.).

La dépréciation des Africains sur base de la couleur de leur peau atteint son paroxysme avec certaines croyances véhiculées dans le monde musulman, selon lesquelles un Noir, une fois arrivé au Paradis, devient Blanc, comme s'il s'agissait d'une récompense (Lewis, 1982 : 44). Dans le même ordre d'idée, le poète Suhaym, cité plus haut, considérait que « si sa peau est noire, son caractère lui, est blanc » (Lewis, $1982: 29$ ). De telles considérations se retrouvent aussi dans les poèmes de 'Antara, qui fait régulièrement allusion à la couleur de sa peau et à la perception qu'avaient ses contemporains des Africains (voir le Dìwān de 'Antara).

Cette dépréciation de l'africanité dans ses caractéristiques physiques a été partiellement assimilée par certains Africains : on a parlé plus haut des Gosha de Somalie et du terme jareer, qui les désigne péjorativement. Précisons que jareer, qui fait référence à leurs cheveux crépus, les traits de leurs visage et leur peau noire, s'oppose aux termes jileec (doux) et bilis, qui sont eux appliqués aux Somali « purs », et que le premier terme renvoie clairement à l'africanité, opposée à l'arabité des Somali (Besteman, 1995: 47 sq.). Une légende qui a cours parmi les clans sédentaires somaliens fait d'ailleurs des Somaliens aux traits africains les descendants d'un géant malfaisant. Ce dernier, nommé Geeddi Abaabow, faisait régner la terreur sur le clan des Eelay et exerçait le droit de cuissage sur les jeunes filles. Pour sauver la virginité de sa sœur, un certain Kuma fit en sorte de gagner la confiance du géant. Il réussit à scier les dix arcs dont se servait le despote pour tuer ses ennemis, puis il ouvrit les portes de son palais afin que les Eelay puissent l'investir. Avant de mourir, Geeddi Abaabow aurait dit aux esclaves africains qui étaient présents : «Que tous ceux qui ont la peau noire, les lèvres épaisses, le nez aplati, les cheveux crépus, des grandes mains, des grands pieds et une grande verge, sachent qu'ils sont ma descendance » (Bader, $2000: 98$ ).

On retrouve des histoires similaires en Afrique de l'Ouest. A titre d'exemple, il existe auprès de certains marabouts sarakollé du Sénégal - désireux encore une fois de légitimer 
leur science - une étymologie populaire expliquant leur ethnonyme : il viendrait de deux termes soninke, « sere »-qui signifie une personne - et «xulle », c'est-à-dire blanc, prêtant ainsi une ascendance blanche (Drame, $1996: 66$ ).

Mais le phénomène dépasse le monde musulman. Ainsi, certains Amhara d'Ethiopie tiennent eux aussi à se distinguer physiquement des Africains. Dans l'un de ses romans, D. Worku fait lire à l'un de ses personnages «La Révélation de Marie », qui interdirait aux fidèles éthiopiens de fauter avec « des musulmans, des Gallas [Oromos], des Falashas ou des Africains » (Worku, 1981:26). Toujours en Ethiopie, il semble que les Shankilla, habitant dans l'Ouest du pays, soient dénigrés tant par les Amhara que par les Oromo à cause de leur couleur foncée (Baxter, 1994 : 173). On pourrait encore multiplier les exemples.

On retrouve même ce comportement en dehors du continent africain, en fait partout où l'africanité est liée à l'esclavage : en Amérique latine, le concept de blanqueamiento a fortement contribué à l'effacement des traits culturels africains, et ce jusqu'à nos jours. Ainsi, les Africain(e)s amélioraient leur statut social - parfois même légal - en épousant des Européens (Philips, 1996: 6 sq.). Au Brésil, où la présence africaine est a priori la plus marquée en Amérique latine, l'avancement social semble lui aussi souvent lié à l'éclaircissement de la peau. A la fin des années cinquante, un journaliste américain effectua un reportage de six semaines dans la communauté afro-américaine des états du Sud. Ce reportage était d'autant plus spectaculaire que Griffin « se transforma » en Noir, à l'aide d'un traitement médical, dans le but de vivre les problèmes de la communauté noire de l'intérieur. Au fil de son voyage, il rencontra plusieurs individus éprouvant de la honte, voire un rejet de leurs origines africaines, parfois accompagné de la mise en valeur d'origines européennes, feintes ou réelles. C'est ainsi qu'un homme âgé au teint très foncé lui explique que les Noirs eux-mêmes «ont plus de considération pour un mulâtre, avec des cheveux aplatis, lissés ». Ailleurs, après avoir discuté avec plusieurs interlocuteurs afro-américains, l'auteur réalise que ceux-ci souffrent d'une double discrimination : celle des autres, mais aussi la leur, « le mépris qu'ils ont pour cette noirceur associée à leurs tourments ». Plus tard, lors d'un voyage en bus, il croise un Noir proférant des insultes racistes à l'encontre des autres voyageurs afro-américains, avant d'annoncer « avec fierté [qu'il n'est] pas un Noir de race pure », mais qu'il a des origines française, portugaise et indienne (Griffin, $1962: 52$ sq, 67 sq, 89 sq.).

Les causes de ce rejet de l'africanité sont complexes, mais elles sont bien sûr liés à la honte de l'origine servile et au statut social inférieur conféré aux Noirs après l'abolition de l'esclavage. La vision négative de l'apparence physique est liée aussi à toute une série de théories racistes pseudo-scientifiques au caractère encore plus insidieux - infériorité intellectuelle et morale des Africains, influence du climat sur la personnalité et les moeurs... -qui renforce encore cette impression. Notons qu'un tel sentiment est observable au sein de toute communauté brimée, mise socialement au ban de la société. Ainsi, le phénomène de la «haine de soi » dans la communauté juive, porté à son paroxysme par Otto Weininger, Juif autrichien qui écrivit un virulent ouvrage sur l'infériorité morale et intellectuelle des Juifs, a également déjà été mise en évidence (Lewis, 1987 : 123).

Quant au concept de "métissage », qu'A. Mazrui considère comme étranger à la mentalité arabo-islamique, il suffit d'ouvrir le Lisān al- 'Arab, dictionnaire remontant au $13^{\mathrm{c}}$ siècle, et de regarder la définition de termes comme khilāsì, hajīn ou muwallad pour se rendre compte que ce concept est présent depuis longtemps dans la mentalité arabe, même s'il est toutefois vrai que dans de nombreux cas, la descendance d'un Arabe et 
d'une Africaine sera considérée comme arabe. Le Lisān al-'Arab explique que khilāasi est dérivé du verbe khalas, qui signifie notamment : être en partie tel et en partie tel, mais surtout en ce qui concerne les couleurs. Le mot décrit également les cheveux grisonnants, plus exactement le mélange entre des cheveux noirs et des cheveux blancs (nous dirions 《 poivre et sel »). Le khals est un pâturage où les herbes fraîches et vertes côtoient les herbes desséchées, jaunies. C'est aussi une tache blanche sur un fond noir. Enfin, khilāsi décrit une personne née d'un père blanc et d'une mère noire ou bien d'un père noir et d'une mère blanche (Ibn Manzūr, 1992, 6) : 65).

Quant au terme hajīn, il signifie aujourd'hui «métis ». Mais le sens premier de ce terme donné par le Lisān al- arab est littéralement: «Arabe né d'une captive (imma), naissance honteuse car il est élevé par sa mère ". Une autre définition est "fils d'un Arabe et d'une non-arabe. Cela se dit de quelqu'un dont la couleur blanche a rougi, car les Arabes appellent les étrangers les «Rouges » (hamrā) » (Ibn Manzūr, 1992, (13) : 531). Ainsi, non seulement la notion de métis existe depuis longtemps, mais en plus on y retrouve l'association de la femme non-arabe et de la captive. Le terme hajin garde en tout cas aujourd'hui une connotation négative (Wehr, $1961: 1020$ ).

Le mot muwallad, lui est intéressant car il ne fait aucunement référence à la couleur de la peau. Il s'agit d'un substantif dérivé du verbe wallada: accoucher, engendrer, élever (un enfant). Le premier sens du terme muwallad est donc «né, produit, généré, élevé ». Il peut également signifier «né parmi les Arabes, élevé parmi leurs enfants et selon leurs coutumes », tandis que talìd, de la même racine, signifie « celui qui est né en terre étrangère ('ajam) mais qui a été apporté et élevé en terre arabe » (Ibn Manzūr, 1992, (3) : 469). Le terme muwallad est encore couramment utilisé actuellement, par exemple au Yémen pour décrire les enfants nés d'un père arabe et d'une mère éthiopienne ou somalienne. Un autre terme issu de la même racine, walìd, signifie, enfant, avec quelquefois le sens précis d'esclave né dans la maison du maître. Dans ce cas, il semble donc que le terme mette l'accent sur l'aspect biologique, puis socio-culturel du métissage.

\subsection{L'africanité de l'autre}

Le rejet de l'africanité revêt encore une autre dimension : cette africanité, prise dans le sens de « non-arabité », est quelquefois utilisée par un peuple ou une communauté pour en discréditer une autre, pour expliquer son statut de paria.

Le cas des Midgo des Tumaallo et des Yibro, en Somalie, est assez révélateur. Il s'agit de communautés, appelées sab dans le Nord du pays et bon dans le Sud, situées au bas de l'échelle sociale dans la société somali : ils exercent des professions jugées dégradantes, le droit coutumier leur attribue un statut discriminatoire, ils sont exclus des généalogies que nous avons déjà invoquées, ils sont généralement méprisés par les autres clans. Les Somali avancent diverses explications à cette discrimination : tantôt les ancêtres des sab/ bon auraient utilisé une arme impure, tantôt ils auraient violé un interdit alimentaire. Une autre justification de leur statut est particulièrement intéressante : ils seraient les descendants d'un chef ayant refusé ou combattu l'islam. Ainsi, certaines traditions rapportent que les Migdo sont les descendants d'un certain Abu Jahhal, un Chrétien qui combattit le Prophète Muhammad lui-même. Plusieurs variantes d'une même légende, largement répandue en Somalie, font état de l'affrontement entre Yussuf Kawneyn, appelé aussi Aw Barkhadle, saint homme venu d'Arabie ou d'Egypte, quelquefois considéré comme un Qurayshī, et Maxamed Xaniif, tantôt guérisseur venu d'Egypte, tantôt roi. Le 
premier aurait introduit l'islam en Somalie, tandis que le second dut s'effacer devant le pouvoir du nouveau venu (Bader, $2000: 36 \mathrm{sq}, 83 \mathrm{sq}$.).

Mais il est intéressant d'observer que si ces parias de la société somali sont exclus des généalogies des clans somali, eux-mêmes en tout cas se prêtent bien des origines nobles. Ainsi, ils se considèrent souvent Somali de haute naissance, mais ils seraient rejetés parce qu'à la suite d'une migration, ils auraient été accueillis par des tribus ignorant tout de leurs origines. Certains clans sab/bon revendiquent même eux aussi des origines arabes. C'est le cas des Xoryeelo qui prétendent venir d'Oman, mais aussi des Ugaslabe et des Yaxar, qui prétendent venir de la Péninsule arabique. Certains Yibro se disent même d'origine juive (Bader, $2000: 27 ; 40 ; 133$ ).

Le cas des akhdām, au Yémen, est assez semblable. Il s'agit de communautés arabophones d'origine africaine qui vivent encore aujourd'hui dans des bidonvilles en périphérie des villes. Considérés comme de véritables parias, ils vivent essentiellement de la mendicité et de petits métiers. Les origines des $a \underline{k h} d \bar{a} m$ sont assez obscures, mais leur nom « esclaves, serviteurs » traduit une origine servile, qui expliquerait leur place de paria encore dans la société actuelle. Pourtant, des traditions yéménites qui circulent encore aujourd'hui leur prêtent une généalogie bien particulière : il s'agirait des descendants d'Abrāhā, roi éthiopien de la période pré-islamique, qui envahit la péninsule arabique, accompagné de son armée et d'éléphants, et qui tenta notamment d'envahir La Mecque. Après sa défaite, Abrāhā - dont parle la $105^{\mathrm{c}}$ sourate (al-Fīl, « l'Eléphant ») du Coran - aurait été bouté hors de la Péninsule. Les soldats qui n'auraient pas pu le suivre se seraient installés au Yémen, où ils seraient toutefois restés au ban de la société (Rouaud, 1979 : 146 sq.).

\subsection{Influences européennes}

Un dernier aspect à aborder est l'influence de la colonisation européenne et des théories raciales/racistes qui l'accompagnèrent. Les fantasmes alimentés depuis des siècles sur ces terres inexplorées, et encore une fois la différence physique et le décalage matériel de leurs civilisations par rapport au contexte européen persuadèrent les Européens qu'ils avaient affaire à des sauvages.

Ces préjugés raciaux, aussi extrêmes que tenaces, poussèrent les «explorateurs » européens, puis les missionnaires et les colons qui leur succédèrent, à remettre systématiquement en question l'africanité des populations qu'ils rencontraient et qui ne « collaient » pas à la description du parfait sauvage.

C'est ainsi que les premiers Européens à pénétrer dans la région des Grands Lacs furent profondément étonnés du degré d'organisation et de culture - selon leurs propres critères - des populations avec lesquels ils entraient en contact. Plutôt que de revoir leurs préjugés sur l'infériorité naturelle des Africains, ils leur parut plus réaliste d'imaginer des migrations de populations blanches qui se seraient mêlées autrefois aux Africains. Ils développèrent alors la théorie de l'origine hamitique, sémitique, voire caucasienne des Tutsi au Rwanda et au Burundi et des Hima en Ouganda, destinés à régner respectivement sur les Hutu et les Ira, qui seraient eux de purs Bantous ${ }^{19}$. Répétées par de nombreux observateurs occidentaux, ces théories furent petit à petit intériorisées par les Africains 
eux-mêmes. Ainsi, au Rwanda et au Burundi, les intellectuels tutsi commencèrent à mettre en avant leurs origines éthiopiennes, les Hutu faisant de même avec leurs origines bantoues (Chrétien, 1999 : 281 sq.). Chacun connaît aujourd'hui les tristes conséquences de ces thèses, qui n'avaient pourtant aucun fondement historique ou linguistique ou aucun écho dans les traditions locales.

Au $19^{\circ}$ siècle, ces théories étaient appliquées partout où l'A frique « étonnait », faisant fi de toute cohérence géographique ou historique. Ainsi certains chercheurs attribuèrent aux Phéniciens l'édification des constructions en pierre du Zimbabwe, tant il paraissait impensable que des Noirs aient pu réaliser de tels chefs-d'œuvre. Pour certains, il était tout aussi inconcevable que l'art et l'architecture de l'Egypte pharaonique soient le fait d'Africains. Il fallait donc soit nier l'africanité de cette civilisation - quel qu'en soit le degré - soit nier le statut de civilisation à la culture pharaonique... (Bernal, 1996:499, 938).

De manière générale, 1'origine «sémitique » de ces peuples africains «civilisés » était la théorie la plus souvent avancée. Parce que l'Ethiopie était géographiquement proche, mais aussi sans doute parce que les explorateurs européens en Afrique centrale se voyaient systématiquement devancés par les marchands arabes dans chaque région où ils pénétraient ${ }^{20}$.

L'Encyclopedia Britannica de 1911 expliquait que « les Swahili sont le résultat d'un long croisement entre Nègres et Arabes (...). Leur énergie et leur intelligence, dérivées de leur sang sémitique, leur ont permis de jouer un rôle prépondérant dans le développement du commerce et des industries » (Mazrui et Shariff, $1994: 29$ ).

Cette manie de chercher une origine arabe derrière chaque trait culturel « appréciable » - selon les critères des observateurs européens de l'époque - conduisit même certains linguistes à arabiser le kiswahili plus qu'il ne l'était. En effet, le kiswahili a été standardisé par les Européens, qui d'abord choisirent arbitrairement comme modèle la variante parlée à Zanzibar - plus arabisée sur le plan lexical, et qui ensuite créèrent les néologismes qui leur étaient nécessaires sur base de l'arabe (Mazrui et Shariff, 1994 : 55 sq.; Khalid, 1977 : 113 sq.). Un exemple particulier et lourd de sens est celui du mot ustaarabu, dont nous avons déjà parlé plus haut, qui signifie «culture » en kiswahili, mais qui dérive de l'arabe ista'raba, "s'arabiser ». Selon Khalid, ce mot n'était à l'origine utilisé spécifiquement qu'à Zanzibar et de plus il ne fut introduit que tardivement dans le vocabulaire, au début de ce siècle. Par contre il existe deux autres termes en kiswahili pour désigner la culture et qui ne font pas référence à l'arabité : tamadunu, de l'arabe tamaddun, "culture, civilisation ", et ungwana (Khalid, $1977: 91$ ).

En Afrique de l'Ouest, ce sont les Peuls à qui les chercheurs occidentaux ont prêté quantité d'origines: égyptiennes, malaises, indonésiennes, dravidiennes, romaines, hamites, éthiopiennes et même juives ! (Drame, 1996 : 142)

Mais le plus significatif est que nombre de ces théories importées d'Europe ont été largement ou en partie intériorisés par les Africains eux-mêmes, malgré leur inexistence, dans la plupart des cas dans les traditions locales.

Hormis l'influence de ces théories, le colonialisme a aussi eu une incidence plus directe sur l'identité en Afrique. Selon Mazrui et Shariff, les Britanniques ont volontairement mis en évidence les origines arabes des Swahili dans le but d'associer aux yeux des Africains 
les Arabes et l'islam à l'esclavage d'une part, les Européens et le christianisme à la liberté. Ils prennent pour exemple le livre de J. Mbotela, Uhuru wa Matumwa, «La libération des esclaves ». Ce livre, écrit en kiswahili en 1934, qui dépeint les musulmans comme des esclavagistes et les Européens comme des libérateurs, devint un ouvrage scolaire de référence au Kenya (Mazrui et Shariff, 1994 : 35). Cet argument est intéressant, même s'il est dommage qu'encore une fois les deux auteurs tentent parallèlement de minimiser l'importance de l'esclavage pratiqué en Afrique par les Arabes.

Dans le cas particulier des musulmans de la côte de l'A frique Orientale, le système de taxation et les opportunités d'emploi offertes aux non-Africains jouèrent également un rôle dans l'évolution de leur identité. En 1901, l'administration britannique soumit les « natives » du Kenya à une taxe particulière, appelée « native hut tax ». Dans un premier temps, les Swahili devaient s'y soumettre au même titre que les Africains. De ce fait, de nombreux Swahili décidèrent peu à peu de revendiquer un statut d'étranger - en mettant en exergue leurs origines arabes ou asiatiques - afin d'échapper aux désavantages du système de taxation (Mazrui, 1994 : 37). Parallèlement, les musulmans qui se définissaient comme Arabes et non plus comme Africains, étaient associés aux Asiatiques et accédaient de ce fait à un statut social plus élevé, mais aussi à une rémunération plus élevée pour un même travail. Ceci aurait poussé de nombreux musulmans africains de la région à revendiquer une ascendance arabe (Mazrui, $1973: 68$ ).

Mais la présence coloniale eut aussi des répercussions indirectes sur la question identitaire des musulmans d'Afrique. Si l'on en croit Muhammad Al-Nuwayhī, si les premières générations de poètes soudanais de l'époque moderne se montrèrent particulièrement liés aux valeurs de l'islam et à la littérature arabe classique, au détriment de la culture africaine qui était pratiquement exclue de leur intérêt, ce fut à cause du sentiment d'humiliation des Soudanais après leur défaite contre les forces angloégyptiennes, qui avaient besoin d'être rassurés psychologiquement. Or, ils ne pouvaient trouver ce réconfort ni dans le passé de l'Afrique, ni dans les réalités de l'Afrique contemporaine. C'est pourquoi ils tournèrent le dos à l'A frique pour regarder plutôt vers le passé glorieux du monde arabo-musulman (Abd Al-Rahim, 1973 : 38).

\subsection{Islamisme, arabisme et pragmatisme politique}

A l'époque contemporaine, l'influence de certains mouvements islamistes constitue un dernier élément favorisant les thèses arabisantes développées par certains Etats ou partis politiques africains. En effet, l'islamisme politique entretient parfois des rapports assez étroits avec la question identitaire arabe.

Il faut dire que le nationalisme arabe lui-même, centré au départ sur la communauté de langue et élaboré notamment par des intellectuels arabes chrétiens, a peu à peu intégré l'islam comme l'une de ses caractéristiques fondamentales. Ainsi, la plupart des mouvements nationalistes arabes faisaient malgré tout référence à l'islam, au moins comme sphère culturelle (Carré, 1993). Après l'échec du nationalisme arabe comme idéologie porteuse au Proche-Orient - on songe au nassérisme, aux organisations comme l'OLP - certains mouvements islamistes ont pris le relais. Mais à leur tour, ils ont souvent récupéré une dimension nationaliste, comme le marxisme l'avait déjà fait ailleurs (Munson, 2000: 10).

En Afrique, le régime islamiste de Khartoum considère que le Soudan est une république arabe et islamique. Même si, comme on l'a vu, la question de l'opposition 
entre l'arabité et l'africanité remonte bien avant le régime actuel, ce dernier a en tout cas nettement tranché pour la première comme identité nationale. Un autre exemple est celui de l'Erythrée, où les islamistes insistent à dessein sur l'ancienneté de la présence arabe dans le pays, tentant même d'arabiser certains aspects africains de la culture du pays. C'est ainsi qu'ils soutiennent que les Bānī 'Āmir, répartis entre l'Erythrée et le Soudan et parlant une langue distincte de l'arabe - le bedawi, langue couchitique - constituent un peuple d'origine arabe, qui serait originaire du Sud de la péninsule arabique et dont des tribus apparentées vivraient encore actuellement au Yémen. Leur arabité aurait continuée à être assurée à travers les siècles par les migrations successives d'Arabes traversant la Mer Rouge (Khayr, 13/1/1997: 7). Ils lient parallèlement la reconnaissance de l'arabe comme une langue officielle du pays au discours islamiste (Yāsīn Muhammad 'Abdallah, 6/1/1997:8).

Quant au Tchad, les références du Frolinat dans les années soixante, puis des autres mouvements « arabisants », à l'arabité du pays ou tout au moins à la langue arabe, reflètent elles aussi des simplifications et des raccourcis historiques, identifiant l'ancienneté de l'usage de l'arabe dans le pays à une uniformisation culturelle tronquée (Jullien de Pommerol,1997: 75).

Notons que cette tendance dépasse l'Afrique noire. En Algérie par exemple, les Kabyles furent dès l'indépendance visés par l'amalgame fait par le pouvoir entre arabité et islam - amalgame juxtaposé sans difficulté au discours nationaliste et socialiste du FLN - facilitant notamment le refus de toute velléité de revendication autonomiste ou indépendantiste (Yefsah, $1992: 106$ sq.).

Dans le même ordre d'idée, la quête d'arabité de certains Africains musulmans relève plutôt du pragmatisme politique. Dans le cas de l'Erythrée, rappelons que pendant la guerre d'indépendance menée contre l'Ethiopie, le Front de Libération Erythréen (FLE) jouait sur le thème de l'arabité de l'Erythrée dans l'espoir de trouver un soutien financier ou au moins diplomatique de la part du monde arabe. Après l'accession de l'Erythrée à l'Indépendance, le gouvernement d'Isaias Afewerki a joué sur le statut de la langue arabe et surtout sur l'adhésion de son pays à la Ligue arabe, au gré de l'état de ses relations diplomatiques avec les pays arabes (Luffin, 1997 : 11 sq.).

Par ailleurs, d'aucuns affirment, même parmi les Somaliens, que si la Somalie est membre de la Ligue arabe, c'est moins par fibre « nationale » que par intérêt économique. Dans le même ordre d'idée, en 1996 une tribu somalienne qui fuyait le chaos politique de la région, revendiquait des origines yéménites - leurs ancêtres auraient émigré de la péninsule arabique et se seraient installés en Afrique voici quelques siècles - et demandait au Yémen de la laisser s'installer sur son territoire.

Dans le cas du Soudan où cohabitent une multitude de peuples différents, il est évident que l'arabisation culturelle qui accompagne l'islamisation du pays a apporté un haut degré d'unité culturelle et de cohésion sociale, comme on l'observe dans le Nord du pays et comparativement à la partie méridionale du pays (Abd Al-Rahim, 1973 : 34). Au Tchad, l'adoption de plus en plus large de l'arabe vernaculaire comme langue véhiculaire - perdant par la même occasion son caractère " ethnique »-entraîne lui aussi des avantages similaires, dans un pays où le gouvernement reconnaît officiellement pas moins de 108 langues (Jullien de Pommerol, 1997 : 51 sq.).

Enfin, il arrive que certains Africains revendiquent quelque origine prestigieuse pour se défendre contre l'arabisation ou simplement pour contrer le poids politique de leurs adversaires. Ainsi, à Zanzibar, dans les années cinquante, des activistes africains 
créèrent le « Parti Afro-Shirazi », référence explicite à leur africanité d'une part, et à une civilisation qui n'avait rien à envier à celle des Omanais d'autre part. Cette organisation politique, qui mènera la révolution de 1964, prit ouvertement position contre le pouvoir colonial britannique mais surtout contre les Arabes d'origine omanaise, qui détenaient le pouvoir politique et économique (Freeman-Grenville, 1998 : 499b). De même, certains Dinka du Sud du Soudan considèrent qu'ils descendent des Ja'alīn, tribu arabe du Nord du pays, ce qui leur permet d'établir la légitimité de leur présence dans la région sur base des mêmes critères que le gouvernement (Al-Wasat, 13/11/2000:6).

\section{Mise en valeur de l'africanité}

\subsection{Dans la culture arabe}

Malgré les exemples cités plus haut, la couleur noire de la peau ne fut pas systématiquement péjorative chez les Arabes, selon les époques et les lieux. Elle fut parfois même considérée comme un indice de beauté... voire de pureté. Ainsi le Lisān al'Arab, encore une fois, précise que si le terme $a k h d a r$ - couramment traduit par « vert »désigne généralement les Africains, il peut aussi désigner les Arabes eux-mêmes.

Voici ce que nous apprend cet ouvrage :

"Akhdar : le premier sens de ce terme est "vert» (...). S'agissant de la couleur de la peau, il est synonyme d'as-sumra (terme désignant une peau foncée ou noire).

Al-Lahabi a dit:

"Je suis le Vert, qui me connait?

Vert de peau dans la maisonnée des Arabes".

L'homme veut dire par ces vers: je suis pur, car la couleur de la peau des Arabes est noire.

Il y a deux explications données à ce vers. La première est qu'il sous-entend la noirceur de la peau. Selon Abū Tälib le grammairien, il veut dire qu'il fait partie des Arabes purs et authentiques car le noir est la complexion la plus répandue chez les Arabes.

Selon Ibn Barrī, al-Jawharì a attribué ce vers à Al-Fadl Bin al-'Abbās bin 'Utbãtì Bin Abì Lahabì, qui par "vert" voulait dire la couleur foncée. Il veut ainsi souligner la pureté de sa filiation et dire qu'il est un Arabe authentique. Car on décrit la couleur des Arabes par le noir et celle des 'Ajam ${ }^{21}$ par le rouge (...). C'est dans ce sens aussi qu'il faut comprendre les paroles de Miskin ad-Därimï :

Je suis Miskin, pour ceux qui me connaissent,

Ma couleur est noire (akhdar), c'est la couleur des Arabes (...) "

(Ibn Manzūr, 1992, (4) : 245 sq.).

Ainsi, la couleur de peau foncée, voire noire, serait associée ici à l'arabité dans ce qu'elle a d'authentique. Un autre passage du Lisān al-'Arab renforce cette idée. Il s'agit 
de l'interprétation à donner au hadīth «j'ai [le Qur'ān] été envoyé à l'homme rouge et à l'homme noir ", que nous avons déjà cité plus haut. L'ouvrage précise qu'il faut entendre par «Noirs » les Arabes et par «Rouges » les 'Ajam, c'est-à-dire les non-arabes (Ibn Manzūr, 1992, (13): 431).

Plusieurs auteurs arabes ont également insisté sur l'association entre la peau foncée et l'arabité authentique. Certaines anecdotes dépeignent même des linguistes arabes, tel Kisā' $\overline{1}$, grand grammairien du $9^{e}$ siècle, heureux de voir foncer leur peau, car cela leur faisait ressembler aux Bédouins, qu'ils adulaient. Un autre linguiste, qui aimait qu'on le surnomme « le Bédouin » ou « le Noir », allait jusqu'à s'enduire la peau d'huile afin de bronzer et de mériter son surnom²2.

L'association entre arabité et africanité ou peau foncée se retrouve dans d'autres langues, probablement par contamination de l'arabe. Ainsi, il est intéressant de noter qu'en turc le sens premier du terme Arap signifie forcément "Arabe », dont il s'agit d'ailleurs de la simple transcription (selon D'Herbelot, les Tures appelaient anciennement les habitants de l'intérieur de la Libye Kara Arap, « les Arabes Noirs », pour les distinguer des Arabes au teint plus clair (D'Herbelot, 1697 : 522)). Mais en turc, Arap désigne aussi quelqu'un ayant la peau très foncée ou noire. Le terme se retrouve également dans des expressions où le sens de «noir, africain » est évident. C'est le cas d'arap köle ou arap cariye, qui désignent l'esclave non pas arabe mais bien africain, ou d'arap saçı, littéralement « chevelure d'arabe », qui désigne les cheveux crépus, et par extension une histoire embrouillée (!) (Tuğlac1, 1984 : 49) Le terme zenc, translittération de l'arabe zanj, existe également pour désigner les Africains. Le grec moderne, qui connaît le terme araps depuis longtemps, en a certainement emprunté le même double sens au turc, puisqu'il signifie également soit Arabe, soit Africain.

En outre, plusieurs auteurs arabes - à des époques et dans des contextes certes assez divers - ont rédigé des opuscules faisant l'éloge des Noirs : le Tanwìr al-ghabash fi fadl as-Sūdān wa'l-Habash, de Ibn al-Jawzī (12 siècle), le At-tirāa al-mankü $\underline{\text { sh }}$ fi mahāsin $a l-h u b u \bar{s} \underline{s}$, de Muhammad ibn al-Bāqī (16e siècle (Histoire générale de l'Afrique, (1997 : 404. Mais l'ouvrage le plus connu est sans doute le Fakhr as-Südān 'ala al-Baydān d'alJāhiz, cité plus haut, qui met en valeur les personnalités noires ayant joué un rôle dans le monde arabo-islamique, mais aussi les nombreuses expressions où la couleur noire a un sens positif ${ }^{23}$ Cela dit, ce livre est assez équivoque, étant donné les préjugés très défavorables aux Africains que l'on retrouve dans le reste de l'œuvre d'al-Jāhiz, comme le Kitāb al-Bukhalā', le Kitāb al-hayawān ou le al-bayān wa'l-tabyīn (Lewis, 1982 : 35 $\mathrm{sq)}$.

Plus proche de nous, l'écrivain contemporain soudanais Tayyib Sālih précise la noirceur de la peau est considérée comme un critère de beauté par certains de ses compatriotes, qui composent même des chants sur le thème du « beau garçon noir » ${ }^{24}$.

22 Les premières générations de grammairiens arabes considéraient que les Bédouins étaient les détenteurs de la langue classique authentique, ce qui explique l'admiration que leur vouaient les linguistes de l'époque. Voir Touati, H. $2000: 73$ et 77.

23. Pour une traduction française, voir Ducatez, 1983.123.

24. Interview de T. Sālih parue dans al-Wasat, Londres, 7-14 septembre 1998 : 48 à 52 et 56-57. 


\subsection{En Afrique}

Si la quête d'arabité revêt une importance particulière en A frique musulmane, elle n'est bien sûr pas systématique. En effet, certaines communautés ou certains peuples assument totalement le fait d'être à la fois musulmans et africains, sans nécessairement gommer ce dernier trait au profit d'une éventuelle ascendance arabe. Il serait donc extrêmement réducteur de considérer que chaque peuple africain musulman se prête systématiquement des origines arabes.

En Erythrée par exemple, l'intellectuel Muhammad 'Uthmān Abū Bakr a consacré un imposant ouvrage à l'Histoire de sa patrie. S'il met souvent l'accent sur l'arabité de son pays, il ne lui donne pas pour autant un caractère exclusif. Selon lui, l'Erythrée moderne est le résultat de la rencontre de plusieurs cultures, notamment la culture arabe : il rappelle que le tigrinya et le tigré font partie des langues sémitiques, au même titre que l'arabe. Il souligne l'ancienneté des rapports entre les populations arabes de la péninsule arabique et la côte nord-est de l'A frique. Il signale également que plusieurs tribus du pays se réclament d'une origine arabe. Mais il souligne d'autre part les aspects proprement africains de la culture érythréenne. Il précise bien que les origines de son peuple sont arabes, mais aussi plus largement sémitiques, couchitiques, hamitiques et nilotiques (Abū Bakr, 1994 : 183).

Dans le centre du Soudan, un leader des Monts Nūba déclarait à la presse voici quelques années qu'il était «musulman mais pas arabe. Cela ne m'empêche pas d'écouter les chansons d'Umm Kulthūm et la poésie arabe. De plus ma femme est chrétienne, et nous n'avons aucun problème d'identité » (al-Wasat, 15/7/1996:21).

Au Kenya et en Tanzanie, certains intellectuels swahili insistent aussi sur le fait que leur peuple est bien africain - tout en assumant les apports culturels arabes - et qu'il ne sont pas le simple résultat d'une migration arabe. D'aucuns tentèrent même de "désarabiser » le kiswahili en tentant de remplacer les mots d'origine arabe par des termes bantous (Mazrui, et Shariff, $1994: 46$ sq; 62).

Le cas des Nubi est particulièrement intéressant: il s'agit d'une communauté musulmane qui vit principalement en Ouganda, mais aussi au Kenya et en Tanzanie. Ils sont les descendants de militaires originaires du Sud du Soudan, qui ont accompagné les troupes britanniques dans leurs campagnes en Afrique orientale et qui se sont finalement installés dans les pays précités à la fin du siècle passé. Or, bien qu'ils parlent une langue particulière qui constitue un «créole » arabe, le kinubi - ils sont donc arabophones - les Nubi ne se considèrent pas comme Arabes mais bien comme un peuple distinct. Ceux que nous avons rencontrés se souviennent d'ailleurs avec fierté de leur tribu d'origine au Sud du Soudan : Bari, Fodjulu, Moru, Dinka, Kakwa, même s’ils ne parlent plus leurs langues d'origine depuis plusieurs générations ${ }^{25}$.

De même, les intellectuels musulmans soudanais ne rejettent pas tous leur passé africain loin de là, et tentent de lui trouver une place dans la culture contemporaine. Dans les années trente, Muhammad Ahmad Mahjūb considérait que le nationalisme soudanais devait se baser tant sur l'islam et la culture arabe que sur les traditions et la terre africaine

25. Recherche effectuée par l'auteur à Bombo (Uganda) en décembre 1999 et à Kibera et Mombasa (Kenya) en janvier 2001. Pour une histoire des Nubi d'Afrique de l'Est, voir Furley, 58, $1959: 311$ à 328 et Soghayrun, 1981. 
(Abd al-Rahim, 1973:41). Muhammad M. Al Fìtūri, poète soudanais arabophone du Nord du pays, insiste beaucoup sur l'africanité de son pays. Il a d'ailleurs rédigé un recueil de poèmes dédiés à l'Afrique : Aghānì Afrīqivā, "Chants d'Afrique ». Il y aborde différents thèmes: son amour pour l'Afrique, l'esclavage, la colonisation... Dans l'un de ses poèmes, anā zanjī, «Je suis Africain », il exprime sa fierté d'être Noir, en faisant clairement allusion aux concepts de l'esclavage et de la honte d'affirmer son identité :

"Dis-le, n'aie pas peur, n'aie pas peur.

Dis le à la face de l'humanité,

Je suis Africain,

Mon père et mon grand-père sont Africains,

Ma mère est Africaine,

Je suis Noir,

Noir mais libre, j'ai la Liberté,

Ma terre, c'est l'Afrique,

Vive ma terre,

Vive l'Afrique!(...)»

(al-Fītūri, $1967: 38$ ).

Tayyib Sālih, auteur soudanais dont la notoriété a atteint l'Occident, assume tout autant l'arabité que l'africanité de la culture soudanaise. Ses romans mettent généralement en scène les deux facettes de la culture de son pays. Il considère d'ailleurs que « les Soudanais sont tous des métis : des Arabes, des Nubiens et des Zunūj (pluriel de Zanjī) qui se sont mélangés $»^{26}$. D'autres auteurs soudanais contemporains, comme le dramaturge 'Abd al'Azīm Hamadnallah' ${ }^{27}$, inspirent régulièrement des racines africaines de leur pays dans leurs œuvres.

Dans les pays africains situés beaucoup plus en marge de la sphère culturelle arabomusulmane, l'Afrique des Grands Lacs par exemple, les communautés musulmanes locales ne semblent pas assimiler islam et arabité. Peut-être est-ce lié au fait que l'islam y a pénétré essentiellement par le biais d'Africains musulmans plutôt que d'Arabes (Luffin, 1999 : 29; Lewis, 1982 : 123; Abel, 1959). Par ailleurs, l'islam y est arrivé assez récemment et de manière souvent plus superficielle. Enfin, le Rwanda et le Burundi n'ont été touchés que tardivement par les marchands d'esclaves musulmans, qui y rencontrèrent d'ailleurs une résistance particulièrement efficace.

Notons également que certains Africains tirent leur fierté non pas d'un ancêtre arabe mais bien de Bilāl. Bilāl était un Africain - un Ethiopien nous disent les sources arabes - qui se convertit à l'islam à l'époque de Muhammad, et qui fut désigné par lui comme premier muezzin. Ainsi, en Afrique subsaharienne, la grande famille des Keita au Mali considère que Bilāl est à l'origine de leur filiation (Clarke, 1984 : 40). Certaines généalogies mandingues font de Bilāl leur premier roi. Pour certains d'entre eux, Bilāl n'était pas un Ethiopien mais un Tchadien, esclave de la cour du roi de Yaoundé, au Cameroun (Laye, 1978: 69). D'ailleurs, la région entourant le lac Fitri, au Tchad, est 
appelée Dār Bilāla, « le pays des Bilāla », où la tribu arabe des Hemat revendique Bilāl comme ancêtre éponyme (Jullien de Pommerol, 1997 : 14).

A Tunis vit une communauté particulière qu'on appelle les « diyār sīdī bilāl ». Ils sont les descendants d'esclaves achetés au Niger et au Mali. L'expression de leur identité est particulièrement intéressante, car s'ils ne cherchent en aucune manière à gommer leurs origines africaines par l'une ou l'autre généalogie « arabe », ils greffent par contre, parallèlement aux origines ethniques dont ils sont parfaitement conscients - bournouane, bagirmienne, haoussa, songhay, bambara - un nasab qui en fait les descendants de Bilāl. Ce nasab est d'ailleurs revendiqué par les autres communautés noires du Maghreb (Rahal, 2000).

Ces généalogies bilāliennes répondent donc différemment au besoin de revendiquer un ancêtre prestigieux, puisqu'ici ce dernier est musulman, mais africain. Dans le cas précis de la communauté africaine de Tunis, d'origine servile, cette généalogie a encore une dimension supplémentaire : elle permet à la fois de combler le vide du nasab - puisqu'il s'agit de populations déportées - et de gommer l'origine servile en question, puisqu'ils ne descendent plus de n'importe quel esclave mais bien d'un compagnon du Prophète.

\section{Conclusion}

Il semble que si la revendication d'origines arabes parmi les musulmans n'est pas systématique en Afrique, elle est en tout cas bien plus développée qu'ailleurs dans le monde musulman non-arabe. Bien sûr, elle est souvent fondée historiquement, les migrations de part et d'autre de la Mer Rouge et à travers le Sahara étant connues historiquement depuis longtemps. Mais dans certains cas, l'ascendance revendiquée ne semble pas toujours correspondre à une vérité historique. En outre, si nous avons réuni les récits mettant en scène une ascendance arabe, nous ne voulons bien sûr pas sous-entendre que l'ensemble des musulmans d'Afrique se considèrent comme Arabes, nous avons d'ailleurs donné certains contre-exemples.

En réalité, nous avons tenté de comprendre pourquoi de nombreux peuples musulmans étaient si attachés à cette filiation, de l'est à l'ouest de l'Afrique. Nous avons de même voulu souligner une certaine gradation de cette revendication, depuis la simple généalogie éponyme au véritable rejet de l'africanité, qu'elle soit culturelle ou même physique.

Nous avons pu cerner différentes causes, finalement assez nombreuses - du phénomène d'arabisation en Afrique : les liens très forts entre religion musulmane et culture arabe, la légitimité politique et spirituelle acquise dans certains contextes par les familles descendant du prophète Muhammad, plus généralement l'importance donnée aux généalogies dans la culture arabo-musulmane, le rejet d'un passé impur associé à la Jāhiliyya, la recherche d'un passé historique et culturel jugé plus glorieux, ou encore de simples calculs politiques. Tous ces éléments ont par ailleurs joué un rôle dans le phénomène d'arabisation du monde musulman en général, au Maghreb et au ProcheOrient par exemple. Mais l'esclavage dont le continent africain fut la proie et le racisme qui y est lié restent, à nos yeux, l'élément prépondérant permettant d'expliquer le rejet de l'africanité et son corollaire, la recherche d'arabité. L'impact de la traite - par son ampleur aussi bien que par sa durée - ne pouvait que marquer l'identité des peuples qui en ont été victimes.

Bien sûr, nous sommes conscient du fait que les exemples que nous avons mentionnés font appel à un cadre très étendu dans le temps et dans l'espace, ce qui implique des 
cas de figure parfois très variables. L'Histoire de l'extension de l'islam au Sénégal est différente de la situation au Soudan par exemple. Par conséquent, aucune des tentatives d'explication ici développées n'abolit forcément les autres. Le cas de la Somalie est révélateur : on y retrouve l'importance du nasab des nomades et du shérifisme, aussi bien que la quête d'une légitimité politique ou spirituelle et le mépris d'une certaine africanité associée à la servitude. Il reste que les séquelles de l'esclavage sont au moins l'un des facteurs décelables dans une grande partie des traditions que nous avons rassemblées.

Mais quelles que soient les raisons de cette quête d'arabité, il est en tous les cas dommage qu'elle se fasse souvent au détriment de l'africanité, quelquefois rejetée, effacée, niée. La Somalie par exemple, perd ainsi un pan significatif de son histoire en niant ses liens avec les cultures africaines : la toponymie du pays trahit pourtant quelquefois une étymologie swahili et des intellectuels somaliens - comme Shaykh Qāsim Bin Muhyi'd-dīn ou Dada Masiti, au siècle passé - ont même rédigé des ouvrages dans cette langue (Kasim, 1995 : 34). D'ailleurs, les historiens arabes médiévaux qui traitent de la Somalie à leur époque la décrivent comme une contrée africaine, peuplée de gens à la peau noire (Zunūj) ou d'Abyssins (Habash, les Arabes faisant la distinction entre Abyssins, Nubiens et Zunūj, ces derniers étant tous les Africains noirs qui ne sont pas inclus dans les deux premiers groupes $)^{28}$. Shihāb ad-Dīn Al-Hamāwi, dans son Kitāb mu 'jam al-buldān, précise explicitement que les Somaliens sont noirs, afin de ne pas les confondre avec les immigrants asiatiques (Mukhtar, 1957, V: 173).

Le Soudan aussi, doté d'une diversité culturelle et linguistique comparable à celle de l'Ethiopie ou du Congo, perdrait un important patrimoine humain s'il parvenait un jour à mener sa politique d'arabisation à terme.

Une piste de recherche ultérieure serait de comparer la quête d'arabité en Afrique musulmane avec les traditions d'origines allogènes ailleurs sur le continent. Certains traits communs ou au contraire divergents permettraient d'affiner les conclusions de la présente recherche.

28. Pour un aperçu de plusieurs sources arabes médiévales sur l'Afrique, voir par exemple Devic, 1993 : $51 \mathrm{sq}$ 


\section{Bibliographie}

Aber A., 1959. Les Musulmans noirs du Maniéma et de la Province Orientale. Bruxelles : CEPMMC.

Abū Bakr, Muhammad, 1994. 'Uthmān, Tarikhh Iritrūyyā al mu'āsir. Le Caire : Abu Bakr.

Abū QÄsim Ai-Andalusī, 1912. Kitāb tabaqāt al-umam. Beyrouth : L. Cheikho.

Abd Al-Rahm, M., 1973. Arabism, Africanism and Self-Identification, in The Southern Sudan, pp. 29-45. Londres : F. Cass.

'Alu AL-'Asīlī (éd.), 1998. Dìwāan 'Antara, Beyrouth : M. al-Nur.

ALıIBfRt, Cl., 1988. Les contacts entre l'Arabie, le Golfe persique, l'Afrique orientale et Madagascar, in L'Arabie et ses mers bordières. Paris : Maison de l'Orient.

Avghelescu, N., 1995. Langage et culture dans la civilisation arabe. Paris: L'Harmattan.

Averroes, 1996. Discours décisif (texte bilingue, traduit par M. Geoffroy). Paris : Flammarion.

Bader, Ch., 2000. Les Yibro, mages somali. Paris : L'Harmattan.

BAXTER, P.T.W., 1994. The Creation and Constitution of Oromo Identity, in Ethnicity and Conflict in the Horn of Africa, pp. 167-186. Londres : J. Currey.

Bernal., M. et A. BLACK, 1996. Black Athena. Les racines afro-asiatiques de la civilisation classique. Paris : PUF.

Berquis, J., 1999. Mémoires des deux rives. Paris : Seuil.

Besteman, C., 1995. The Invention of Gosha, in The Invention of Somalia, pp. 43-62. Lawrenceville : Red Sea Press.

Carre, O., 1993, Le nationalisme arabe. Paris : Payot.

Cerlibl, E.. In Histoire générale de l'Afrique, III : 407 sq.

Chretifn, J. P., 2000. L'Afrique des Grands Lacs. Deux mille ans d'Histoire. Paris : Flammarion.

Chretien, J. P. et J. L. Triald, 1999. Histoire d'Afrique. Les enjeux de la mémoire. Paris : Karthala.

Clarke, B. C., 1984. West Africa and Islam. Londres: E. Arnold.

CoHfN, M., 1971. Hām, in E.I. ${ }^{2}$, III, p. 107a-b. Leiden : Brill.

Coudougnan, G., 1988. Nos ancêtres les pharaons, Dossiers du CEDEJ. Le Caire : CEDEJ.

D'herbel.ot, B., 1967. Bibliothèque Orientale. Paris.

Davidson, B., 1995. African Civilization revisited. New Jersey : Africa World Press.

Declich, F., 1995. Identity, Dance and Islam among People with Bantu Origine in Somalia, in The Invention of Somalia, pp. 191-222. Lawrenceville : Red Sea Press.

Deng, F., 1995. War of Visions. Washington: The Brookings Institution.

DE Moraes, P. F., 1999. Yoruba Origins revisited by Muslims, in Self-Assertion and Brokerage : Early Cultural Nationalism in West Africa, Birmingham (edd. P. F. de Moreas et K. Barber).

DŁvic, L.M., 1993. Le pays des Zendjs, in Islamic Geography, 147. Francfort : Goethe University.

DIOP, B., 1999. Le noir et son pays dans l'imaginaire arabe médiéval, in Sociétés africaines et diaspora, 11, pp. 57-80. Paris : L'Harmattan.

Dıюг, C. A., 1987. L'Afrique noire précoloniale. Dakar : Présence africaine.

Diouf, M., 1994. Sénégal. Les ethnies et la nation. Paris : L'Harmattan.

Drame A., 1996. Peuples du Sénégal. Paris : Sépia.

El Fasi, M., 1997. Histoire générale de l'Afrique, Ill. Paris : Présence africaine. 
FAytūri, Al., 1967. Aghānì Afrìqua. Beyrouth : Dār maktabat al-hayāt.

Freeman-Grenvil..F, G.S.P., 1998. Shīrāzī, in E.I. ², IX, p. 499ab. Leiden : Brill.

Furley, O.W., 1959. The Sudanese Troops in Uganda, in African Affairs, 58, pp. 311-328.

Gıbв, H.A.R., 1963. The Social Significance of the Shu'ubiyya, in Studies in the Civilization of Islam. Boston. Gray, R., 1978. A History of Southern Sudan. Oxford : Oxford University Press.

Grifeis, J. H., 1962. Dans la peau d'un Noir. Paris : Gallimard.

Hamadjaliah, A., 2003. Hakawätī Nabta. Khartoum.

HFylen, W., 1977. Vocabulaire français-kiswahili-français. Kinshasa : Médiaspaul.

HiNDS, M., 1991. Makhzūm, in E.I.', VI, p. 139a. Leiden : Brill.

Holes, C., 1980. Phonological Variation in Bahraini Dialect, Zeitschrift fur Arabische Linguistik, 4, pp. $72-89$.

Hoty, P.M. and M.W. Daly, 1988. A History of the Sudan. New York: Longman.

HLnwick, J. et P.E. Troutr, 2002. The African Diaspora in the Mediterranean Lands of Islam. Princeton : M. Wiener.

Hussein, T., 1996. fi ash-shi'r al-jăhilì. Le Caire : Där an-nahr,

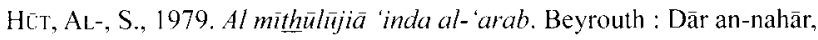

Ibn Battūta, 1990. Vovages (trad. C. Defremery et B.R. Sanguinetti). Paris: Anthropos.

IBN KHALDūn, (éd. non datée). al-Muqaddima. Alexandric : Dār Ibn Khaldūn.

IBґ KHALDŨN, 1997. Al Muqaddima (trad. Française de V. Monteil). Paris : Sindbad.

IвN Manzūr, 1992. Lisān al- Arab, Dār as-Sādir. Beyrouth.

Jimaif. Ahmed, A. (dir.), 1995. The Invention of Somalia. Lawrenceville : Red Sea Press.

Jullien De Pommfroi, P., 1997. L'arabe tchadien. Emergence d'une langue véhiculaire. Paris : Karthala.

KAsı, M. M., 1995. Aspects of the Benadir Cultural History, in The Invention of Somalia. Lawrenceville : Red Sea Press.

Kaisuyoshi, F. et J. Markaris, 1994. Ethnicity and Conflict in the Horn of Africa (Eastern African Studies). Londres-Athènes : J. Currey, Ohio University Press.

Khalid, A., 1977. Liberation of Swahili. Nairobi.

KJ-ZERB(, J. et D.T. NiA.NF. (dir.), 1991. Histoire générale de l'Afrique, IV. Paris : Présence africaine.

Lalon, M., 1988-89. Situation linguistique de la Grande Comore, in Matériaux arabes et sudarabiques, pp. 95-121. Paris.

Laye, C., 1978. Le Maitre de la Parole. Paris : Plon.

Lenselafr, A., 1983. Dictionnaire swahili-français. Paris : Karthala.

LewIS, B.,

1982. Race et couleur en pays d'Islam. Paris : Payot.

1987. Sémites et antisémites. Paris : Fayard.

LuFfIN, X., 1999. Muslims in Burundi, ISIM Newsletter, 3, p. 29. Leiden : ISIM.

MAodisī Al., 1903. Kitāb al-bad'wa-l-tarikh. Paris : Huart.

Manslr, A. O., 1995. The Nature of the Somali Clan System, in The Invention of Somalia, pp. 117-134. Lawrenceville : Red Sea Press. 
Mazrul, A.,

1973. The Black Arabs in a Comparative Perspective, in Southern Sudan, pp. 47-81. Londres : F. Cass. 1964, Political Sex, in Transition.

Matrut, A. M. et I. N. Shariff, 1993. The Swahili. Idiom and identity of an african people. Trenton : Africa World Press.

Mвоw, P., 1999. L'esclavage chez Ahmed Baba de Tombouctou, in Sociétés africaines et diaspora, 11, pp. 81-106. Paris : L'Harmattan,

Movitul, V. M., 1989. Aux cinq couleurs de l'Islam. Paris : Maisonneuve-Larose.

Mukhtлr, M. H., 1995. Islam in Somali History: Facts and Fiction, in The Invention of Somalia, pp. 1-29. Lawrenceville : Red Sea Press,

Munson, H., 2000. Islamism and nationalism, ISIM Nersletter, 5, p. 10. Leiden : ISIM.

Mutanabīi Al., 1994. La Solitude d'un homme (trad. J.-J. Schmidt). Paris : Orphée.

NaIPAul, N. S., 1979. A Bend in the River. London : Random House.

PaLmer, H.R., 1908. The Kano Chronicle, in Journal of the Roval Anthropological Institute, 38, pp. 58-98.

PfFi., J. D. Y., 2000. Religious Encounter and the Making of the Yoruba, Bloomington : Indiana University Press.

Phil.Js, E. (dir.), 1996. Afro-Central Americans : Rediscovering the African Heritage. Minority Rights Group.

QAYSAR Mùsā AL-ZAYn, 1998. Fatrat intishār al-islām wa al-sultanāt, Umm Durmān : al-Haram.

Rnhal, A., 2000. La communauté noire de Tunis. Thérapie initiatique et rite de possession. Paris: L'Harmattan.

Ricard, A., 2000. Voyages de décomertes en Afrique. Paris : Laffont.

Rodın, K. G., 1995. Mansa'atīn : Hikāuāt, qānün, nasab. Asmara.

Roseni1al, F., 1993. nasab, in Encyclopédie de l'Islam, VII, pp. 967b-969a. Leiden-New York : Brill.

Rouaud, A., 1979. Les Yémen et leurs populations. Bruxelles : Complexe.

Sāmır, F., 1954. Thawrat az-zanj. Damas.

Soghayrun, I. E., 1981. The Sudanese Muslim Factor in Uganda. Khartoum : Khartoum University Press.

Stamm, A., 1993. Les civilisations africaines. Paris : PUF.

Tolati, H., 2000. Islam et vovage an Moven-Age. Paris : Seuil.

Trimingham, J. S., 1965. Islam in Sudan. Londres : F. Cass.

TuĞLACı P., 1984. Türkçe-fransızca sözlügü. Istanbul : Inkilâp.

Wa, D. M. (ed.), 1973. The Southern Sudan. The Problem of National Integration. Londres : F. Cass.

Wthr, H., 1961. A Dictionary of Modern Written Arabic. Londres-Beyrouth : Librairie du Liban.

Worku, D., 1981. The Thirtheenth Sun, Londres-Ibadan-Nairobi : Heinemann.

YEFSAH, R., 1992. L'arabo-islamisme face à la question berbère, in Les Kabyles. Eléments pour la compréhension de l'identité berbère en Algérie. Paris : GDM.

ZAWŻ̀̃ī (al-), 1985. sharah al-mu allaqāt as-sab'a. Beyrouth : Dār as-Sādir. 